\title{
The acrylonitrile dimer ion: A study of its dissociation via self-catalysis, self-protonation and cyclization into the pyrimidine radical cation
}

\author{
Henri K. Ervasti ${ }^{\text {a }}$, Karl J. Jobst ${ }^{\text {b }}$, Peter C. Burgers ${ }^{c}$, Paul J.A. Ruttink ${ }^{\text {a }}$, Johan K. Terlouw ${ }^{\text {b, }}{ }^{*}$ \\ ${ }^{a}$ Theoretical Chemistry Group, Department of Chemistry, University of Utrecht, 3584 CH Utrecht, The Netherlands \\ ${ }^{\mathrm{b}}$ Department of Chemistry, McMaster University, 1280 Main St. W., Hamilton, Ont. L8S 4M1, Canada \\ ${ }^{c}$ Laboratory for Neuro-Oncology, Department of Neurology, Erasmus Medical Center, P.O. Box 1738, 3000 DR Rotterdam, The Netherlands
}

Received 21 August 2006; received in revised form 20 October 2006; accepted 23 October 2006

Available online 4 December 2006

\begin{abstract}
Large energy barriers prohibit the rearrangement of solitary acrylonitrile ions, $\mathrm{CH}_{2}=\mathrm{CHC} \equiv \mathrm{N}^{\bullet+}$, into their more stable hydrogen-shift isomers $\mathrm{CH}_{2}=\mathrm{C}=\mathrm{C}=\mathrm{NH}^{\bullet+}$ or $\mathrm{CH}=\mathrm{CH}-\mathrm{C}=\mathrm{NH}^{\bullet+}$. This prompted us to examine if these isomerizations occur by self-catalysis in acrylonitrile dimer ions. Such ions, generated by chemical ionization experiments of acrylonitrile with an excess of carbon dioxide, undergo five dissociations in the $\mu s$ time frame, as witnessed by peaks at $m / z 53,54,79,80$ and 105 in their metastable ion mass spectrum. Collision experiments on these product ions, deuterium labeling, and a detailed computational analysis using the CBS-QB3 model chemistry lead to the following conclusions: (i) the $m / z$ 54 ions are ions $\mathrm{CH}_{2}=\mathrm{CHC} \equiv \mathrm{NH}^{+}$generated by self-protonation in ion-dipole stabilized hydrogen-bridged dimer ions $\left[\mathrm{CH}_{2}=\mathrm{CHC} \equiv \mathrm{N} \cdots \mathrm{H}-\mathrm{C}(\mathrm{C} \equiv \mathrm{N}) \mathrm{CH}\right]^{\bullet+}$ and $\left[\mathrm{CH}_{2}=\mathrm{CHC} \equiv \mathrm{N} \cdots \mathrm{H}-\mathrm{C}(\mathrm{H}) \mathrm{C}(\mathrm{H}) \mathrm{C} \equiv \mathrm{N}\right]^{\bullet+}$; the proton shifts in these ions are associated with a small reverse barrier; (ii) dissociation of the $\mathrm{H}-$ bridged ions into $\mathrm{CH}_{2}=\mathrm{C}=\mathrm{C}=\mathrm{NH}^{\bullet+}$ or $\mathrm{CH}=\mathrm{CH}-\mathrm{C}=\mathrm{NH}^{\bullet+}$ by self-catalysis is energetically feasible but kinetically improbable: experiment shows that the $\mathrm{m} / z, 53$ ions are $\mathrm{CH}_{2}=\mathrm{CHC} \equiv \mathrm{N}^{\bullet+}$ ions, generated by back dissociation; (iii) the peaks at $\mathrm{m} / \mathrm{z}, 79,80$ and 105 correspond with the losses of $\mathrm{HCN}, \mathrm{C}_{2} \mathrm{H}_{2}$ and $\mathrm{H}^{\bullet}$, respectively. The calculations indicate that these ions are generated from dimer ions that have adopted the (much more stable) covalently bound "head-to-tail" structure $\left[\mathrm{CH}_{2}=\mathrm{CHC}=\mathrm{N}-\mathrm{C}\left(\mathrm{H}_{2}\right) \mathrm{C}(\mathrm{H}) \mathrm{C} \equiv \mathrm{N}\right]^{\bullet+}$; experiments indicate that the $m / z, 79\left(\mathrm{C}_{5} \mathrm{H}_{5} \mathrm{~N}\right)$ and $m / z, 105$ $\left(\mathrm{C}_{6} \mathrm{H}_{6} \mathrm{~N}_{2}\right)$ ions have linear structures but the $m / z, 80\left(\mathrm{C}_{4} \mathrm{H}_{4} \mathrm{~N}_{2}\right)$ ions consist of ionized pyrimidine in admixture with its stable pyrimidine-2-ylidene isomer. Acrylonitrile is a confirmed species in interstellar space and our study provides experimental and computational evidence that its dimer radical cation yields the ionized prebiotic pyrimidine molecule.
\end{abstract}

(C) 2006 Elsevier B.V. All rights reserved.

Keywords: Dimer radical cation; Proton-transport catalysis; CBS-QB3 model chemistry; Tandem mass spectrometry; Prebiotic molecule

\section{Introduction}

In the context of our experimental and theoretical studies on self-catalysis in dimer radical cations [1] by proton-transport catalysis (PTC) and related mechanisms [2], we observed that dimer ions of acrylonitrile are readily generated in chemical ionization experiments of the monomer in the presence of a large excess of $\mathrm{CO}_{2}$. The low-energy (metastable) dimer ions primarily dissociate into $\mathrm{m} / \mathrm{z} 54$ ions by self-protonation but $\mathrm{m} / \mathrm{z}, 53$ monomer ions are also generated, either by back dissociation or self-catalysis. Surprisingly, the dimer ions undergo three more competing dissociations. Of these the loss of $\mathrm{C}_{2} \mathrm{H}_{2}$ aroused our

\footnotetext{
* Corresponding author. Tel.: +1 905525 9140; fax: +1 9055222509.

E-mail address: terlouwj@mcmaster.ca (J.K. Terlouw).
}

interest because a collision experiment indicated that the resulting $\mathrm{m} / \mathrm{z} 80$ ions may well be pyrimidine ions [3]. Acrylonitrile is a confirmed species in astrochemistry [4] - it was first detected in the Sgr B2 cloud [5a] and since then also in the cold cloud TMC$1[5 \mathrm{~b}]$ and the atmosphere of Saturn's moon Titan [5c,d]—and a further study of a potential route to the formation of the prebiotic pyrimidine molecule via the above ion-molecule reaction seemed worthwhile.

Ion-molecule interactions have been shown to play a role in the production of larger molecular species in astrochemistry [6] and mass spectrometry has long been an indispensable tool in their study [7]. Ion-molecule reactions are advantageous over neutral-neutral reactions without activation energy because their rate coefficients may be higher by as much as a factor of $10^{4}$ if the molecule is polar [4]. This is the case with acrylonitrile which has a large dipole moment. 
We further note that the search for prebiotic molecular species in the interstellar medium is a subject of considerable interest. The driving force behind this quest lies in the role these molecules may have played in the formation of life on Earth [8]. Thus far as many as 130 molecular species have been identified, largely in the dense regions of dust clouds. Nevertheless, only a handful of biologically important molecules has yet been confirmed [4,9]. An early search for pyrimidine was unsuccessful [10a] but recently this integral DNA component was tentatively identified in the Sgr B2, Orion KL and W51 interstellar clouds $[10 \mathrm{~b}, \mathrm{c}]$. A route to its formation has not been established but it has been suggested that it could be formed by the aggregation of $\mathrm{HCN}$ and acrylonitrile either in the gas-phase or on the surface of dust grains [10a].

In this study, we report the results of a detailed experimental and computational analysis of the rich and complex chemistry of the acrylonitrile dimer radical cation. It will be shown that interaction of an acrylonitrile ion with its neutral counterpart leads to hydrogen-bridged radical cations. These may undergo self-protonation or isomerize into the very stable distonic ion $\mathrm{CH}_{2}=\mathrm{CH}-\mathrm{C} \equiv \mathrm{N}-\mathrm{CH}_{2}-(\mathrm{CH}-\mathrm{C} \equiv \mathrm{N}$ which can be viewed as a head-to-tail dimer and which acts as precursor for the observed losses of $\mathrm{H}^{\bullet}, \mathrm{HCN}$ and $\mathrm{C}_{2} \mathrm{H}_{2}$. The latter process proceeds via cyclization and produces ionized pyrimidine in admixture with its 2-ylide isomer. Self-catalysis, although energetically quite possible, is not observed: this process requires considerable reorientation making it kinetically unfavourable.

\section{Experimental and computational details}

\subsection{Experimental procedures}

The experiments were performed with the VG Analytical ZAB-R mass spectrometer of BEE geometry (B, magnet; $\mathrm{E}$, electric sector) [11] equipped with a standard chemical ionization source operating at $120^{\circ} \mathrm{C}$. The repeller voltage was held close to $0 \mathrm{~V}$ and the primary ionization was accomplished with $100 \mathrm{eV}$ electrons. Gaseous acrylonitrile and $\mathrm{CO}_{2}$ in a ca. 1:10 molar ratio were admitted to the ion source via separate inlet systems at a total indicated pressure (monitored by a remote ionization gauge $)$ of $(7-10) \times 10^{-5}$ Torr.

Metastable ion (MI) mass spectra were recorded in the second field free region (2ffr); collision-induced dissociation (CID) mass spectra were recorded in the 2 and $3 \mathrm{ffr}$ using oxygen as collision gas (transmittance, $T=70 \%$ ). The CID mass spectra of the $2 \mathrm{ffr}$ metastable peaks were obtained in the $3 \mathrm{ffr}$ using $\mathrm{O}_{2}$ as collision gas. For these experiments the maximum available accelerating voltage, $10 \mathrm{kV}$, was used. CID spectra of reference ions having a translational energy close to that of the product ions resulting from (MI or CID) dissociations in the $2 \mathrm{ffr}$, were also obtained in the $3 \mathrm{ffr}$. All spectra were recorded using a PCbased data system developed by Mommers Technologies Inc. (Ottawa).

Acrylonitrile, 2-chloroacrylonitrile and carbon dioxide were of research grade (Aldrich) and used without further purification. The deuterium labeled nitriles $\mathrm{CD}_{2}=\mathrm{CDC} \equiv \mathrm{N}(99.4$ at.\%
D) and $\mathrm{CH}_{2}=\mathrm{CDC} \equiv \mathrm{N}(99.4$ at.\% D) were purchased from $\mathrm{CDN}$ Isotopes Canada.

\subsection{Computational aspects}

The calculations were performed with the CBS-QB3 model chemistry [12] using Gaussian 98 [13a] and 03, Rev C.02 [13b] and (for selected transition state searches) GAMESS-UK [14]. In this model chemistry the geometries of minima and connecting transition states are obtained from B3LYP density functional theory in combination with the 6-311G(2d,d,p) basis set (also denoted as the CBSB7 basis set). The resulting total energies and enthalpies of formation for minima and connecting transition states (TS) in the acrylonitrile dimer system of ions are presented in Table 1. Computational and experimental enthalpies for the monomer ion and various dissociation products from the dimer ions are presented in Table 2. Fig. 3 displays the optimized geometries for the principal species. The correct identity of transition states was verified (where not trivially evident) by means of intrinsic reaction coordinate (IRC) calculations. The complete set of computational results is available from the authors upon request.

A previous detailed CBS-QB3 study of a system of ions of comparable size and complexity [15] argues that a conservative estimate of the error in energies derived from the method is $\pm 2 \mathrm{kcal} \mathrm{mol}^{-1}$ for local minima and $\pm 4 \mathrm{kcal} \mathrm{mol}^{-1}$ for transition states. However, most of the open shell species in the present study have spin-contaminations that exceed the "acceptable" range (0.75-0.79) in the CCSD(T), MP2 and MP4 components of the method. For example, the acrylonitrile ion AN, the pyrimidine ion PY1, the vinylpyrimidine ion VP1 and the dimer ion D1 of Scheme 7 have $\left\langle S^{2}>\right.$ values of $0.99,1.29,1.47$ and 0.97 , respectively. It is difficult to assess the effect of strong spincontamination on the errors in the CBS-QB3 derived energies but the incorporation of a spin-correction factor and the use of DFT derived geometries are expected to mitigate adverse effects [16]. In this context we note, see Table 1, that the available experimental $\Delta_{\mathrm{f}} H_{298}$ values for $\mathrm{AN}$ and PY1, 296 and $260 \mathrm{kcal} \mathrm{mol}^{-1}$, are gratifyingly close to the calculated values, 298 and $260 \mathrm{kcal} \mathrm{mol}^{-1}$, respectively. In the same vein, the $\Delta_{\mathrm{f}} H_{0}$ value of $100 \mathrm{kcal} \mathrm{mol}^{-1}$ for the severely spin-contaminated radical $\mathrm{CH}_{2}=\mathrm{C}^{\bullet}-\mathrm{C} \equiv \mathrm{N}$ (ANR1 in Table $1,<S^{2}>=1.33$ ) is virtually the same as the benchmark value, $100.2 \mathrm{kcal} \mathrm{mol}^{-1}$, obtained in the elaborate theoretical study of spin-contaminated radicals by Mayer et al. [16]. Finally we note that our mechanistic proposals of Scheme 7 remain essentially the same if the energy diagram were based upon the (relative) energies of the CBSB7 component of the method where spin-contamination is not an issue.

However, one anomalous result warrants further discussion. It concerns the hydrogen-bridged radical cations HBRC-1 and HBRC-2 which, unlike HBRC-3 and HBRC-4, show a very large difference in the stabilization energy (SE) derived from the B3LYP/CBSB7 and CBS-QB3 calculations. The DFT calculation yields an SE of $24 \mathrm{kcal} \mathrm{mol}^{-1}$ for both ions whereas the full CBS-QB3 method predicts much lower values: $17 \mathrm{kcal} \mathrm{mol}^{-1}$ for HBRC-1 and $15 \mathrm{kcal} \mathrm{mol}^{-1}$ for HBRC-2. An explanation 
Table 1

Energetic data ${ }^{a}$ derived from CBS-QB3 calculations pertinent to the ion chemistry of acrylonitrile and 2-chloroacrylonitrile described in Schemes 1 and 8

\begin{tabular}{|c|c|c|c|c|c|}
\hline Ionic/neutral species & CBS-QB3 E(total) $[0 \mathrm{~K}]$ & $\mathrm{ZPE}$ & QB3 $\Delta_{\mathrm{f}} H_{0}^{\circ}$ & QB3 $\Delta_{\mathrm{f}} H_{298}^{\circ}$ & Expt $\Delta_{\mathrm{f}} H_{298}^{\circ}$ \\
\hline $\mathrm{CH}_{2}=\mathrm{CHC} \equiv \mathrm{N} \mathrm{ANN}$ & -170.53848 & 31.5 & 48 & 46 & $44^{\mathrm{b}}$ \\
\hline $\mathrm{CH}_{2}=\mathrm{CHC} \equiv \mathrm{N}^{\bullet+2} \mathrm{~A}^{\prime \prime} \mathrm{AN}$ & -170.13793 & 30.4 & 299 & 298 & $296^{\mathrm{b}}$ \\
\hline${ }^{2} \mathrm{~A}^{\prime} \mathrm{AN}$ & -170.08412 & 29.6 & 333 & 332 & - \\
\hline $\mathrm{CH}_{2}=\mathrm{C}=\mathrm{C}=\mathrm{NH}^{\bullet+2} \mathrm{~A}^{\prime} \mathrm{AN} 1$ & -170.16624 & 28.4 & 282 & 281 & - \\
\hline $\mathrm{CH}=\mathrm{CH}-\mathrm{C}=\mathrm{NH}^{\bullet+}{ }^{2} \mathrm{~A}^{\prime} \mathrm{AN} 2$ & -170.15296 & 29.5 & 290 & 289 & - \\
\hline $\mathrm{CH}_{2}=\mathrm{C}-\mathrm{CH}=\mathrm{N}^{\bullet+2} \mathrm{~A}^{\prime} \mathrm{AN} 3$ & -170.08760 & 27.9 & 331 & 330 & - \\
\hline $\mathrm{HC} \equiv \mathrm{C}-\mathrm{C} \equiv \mathrm{NH}^{+}$ & -169.58533 & 23.5 & 277 & 277 & - \\
\hline TS AN $\rightarrow$ AN1 (Scheme 1) & -169.99871 & 25.6 & 387 & 385 & - \\
\hline $\mathrm{TS}$ AN $\rightarrow$ AN3 (Scheme 1) & -170.06537 & 26.2 & 345 & 344 & - \\
\hline TS AN3 $\rightarrow$ AN1 (Scheme 1) & -170.06355 & 25.8 & 346 & 345 & - \\
\hline $\mathrm{CH}_{2}=\mathrm{CH}-\mathrm{C}=\mathrm{NH}^{+1} \mathrm{~A}^{\prime} \mathrm{ANP}$ & -170.83610 & 38.2 & 226 & 224 & $223^{\mathrm{c}}$ \\
\hline $\mathrm{CH}_{3} \mathrm{CHC} \equiv \mathrm{N}^{+1} \mathrm{~A}^{\prime}$ & -170.76564 & 36.7 & 271 & 269 & - \\
\hline $\mathrm{H}_{2} \mathrm{C}=\mathrm{C}-\mathrm{C} \equiv \mathrm{N}^{\bullet} \mathrm{ANR}_{1}$ & -169.87318 & 22.2 & 100 & 100 & - \\
\hline $\mathrm{HC}=\mathrm{CH}-\mathrm{C} \equiv \mathrm{N}^{\bullet} \mathrm{ANR}_{2}$ & -169.86085 & 22.7 & 108 & 107 & - \\
\hline $\mathrm{TS}_{\mathrm{ANR}} \rightarrow \mathrm{ANR}_{2}$ & -169.78975 & 18.7 & 153 & 152 & - \\
\hline $\mathrm{H}_{2} \mathrm{C}=\mathrm{CClC} \equiv \mathrm{N}$ & -629.69426 & 25.8 & 42.6 & 42.5 & - \\
\hline $\mathrm{H}_{2} \mathrm{C}=\mathrm{CClC} \equiv \mathrm{N}^{\bullet+}$ (Scheme 8) & -629.30609 & 25.1 & 286 & 286 & $287^{\mathrm{d}}$ \\
\hline $\mathrm{H}_{2} \mathrm{C}=\mathrm{CClC}=\mathrm{NH}^{+}$ & -629.98240 & 32.5 & 227 & 226 & - \\
\hline $\mathrm{HC}=\mathrm{CCl}-\mathrm{C} \equiv \mathrm{N}^{\bullet}$ & -629.01464 & 17.3 & 104 & 105 & - \\
\hline D1(Cl) (Scheme 8) & -801.07231 & 59.4 & $(290)$ & $(288)$ & $-{ }^{\mathrm{e}}$ \\
\hline $\mathrm{D} 4(\mathrm{Cl})$ & -801.06640 & 58.8 & $(293)$ & $(291)$ & $-{ }^{\mathrm{e}}$ \\
\hline TS D1(CI) $\rightarrow$ D4(CI) (Scheme 8) & -801.00057 & 55.9 & $(332)$ & $(330)$ & $-{ }^{\mathrm{e}}$ \\
\hline $\mathrm{C}_{5} \mathrm{H}_{5} \mathrm{~N}^{\bullet+}(\mathrm{m} / \mathrm{z} 79)($ Scheme 7) & -247.41820 & 49.6 & 297 & 295 & $-{ }^{\mathrm{f}}$ \\
\hline PY1 (m/z 80) (Scheme 7) & -263.53204 & 46.8 & 264 & 260 & $260^{\mathrm{b}}$ \\
\hline PY2 (m/z, 80) (Scheme 7) & -263.52851 & 48.1 & 266 & 263 & $-{ }^{\mathrm{f}}$ \\
\hline TS PY $1 \rightarrow$ PY2 & -263.42505 & 42.9 & 331 & 328 & - \\
\hline $\mathrm{C}_{6} \mathrm{H}_{5} \mathrm{~N}_{2}{ }^{+}(\mathrm{m} / z, 105)($ Scheme 7$)$ & -340.19954 & 58.7 & 281 & 278 & $--^{f}$ \\
\hline TS D4 $\rightarrow \mathrm{C}_{6} \mathrm{H}_{5} \mathrm{~N}_{2}{ }^{+}+\mathrm{H}^{\bullet}($ Scheme 7$)$ & -340.69641 & 59.3 & 335 & 331 & - \\
\hline
\end{tabular}

${ }^{\text {a }} E_{\text {(total) }}$ (in Hartrees, all other components, including the ZPE scaled by 0.99 , are in $\mathrm{kcal} \mathrm{mol}^{-1}$.

b From Ref. [17e].

c From PA = $187.5 \mathrm{kcal} \mathrm{mol}^{-1}[17 \mathrm{~b}]$.

d From IE $=10.58 \mathrm{eV}[17 \mathrm{c}]$ and using the calculated enthalpy of the neutral.

e E(total) refers to B3LYP/CBSB7 energies; the enthalpies were calculated using the CBS-QB3 values of $\mathrm{ANCl}+\mathrm{ANN}$ as the anchor.

f The dissociation levels for the loss of $\mathrm{H}^{\bullet} \mathrm{HCN}$ and $\mathrm{C}_{2} \mathrm{H}_{2}$ in Scheme 7 were obtained from the calculated ionic enthalpies of this table and CBS-QB3 $298 \mathrm{~K}$ values for $\mathrm{H}^{\bullet}, \mathrm{C}_{2} \mathrm{H}_{2}$ and $\mathrm{HCN}$ of $52.1,55.2$ and $31.7 \mathrm{kcal} \mathrm{mol}^{-1}$, respectively.

for this unusually large discrepancy may involve the following. For the related complex $\mathrm{HCN} \cdots \mathrm{H}-\mathrm{C}(\mathrm{CN})=\mathrm{CH}_{2}{ }^{\bullet+}$, in which $\mathrm{HCN}(\mu=3.0 \mathrm{D})[17 \mathrm{a}]$ replaces the acrylonitrile $(\mu=3.9 \mathrm{D})$ [17a] component, the DFT and CBS-QB3 methods yield the same stabilization energy of $15 \mathrm{kcal} \mathrm{mol}^{-1}$. The same value was obtained with the more sophisticated CBS-APNO method. This suggests that the DFT calculation overestimates the stabilization energies for HBRC-1/2. The DFT calculation also yields a much more delocalized charge distribution than expected for an ion-dipole complex, probably because the two components of HBRC-1/2 are identical. In contrast, the DFT charge distribution of the HCN-acrylonitrile complex is as expected: the charge is largely localized on the acrylonitrile moiety. Thus the unrealistic charge distributions and stabilization energies of HBRC-1/2 may well be connected to the "sameness" of their components [18]. We further note that a poor DFT result for the geometries of these complexes may adversely affect the CBS-QB3 derived stabilization energies. As discussed in Section 3.2, HBRC-1/2 are key intermediates in the dissociation chemistry of the dimer ions but precise knowledge of their stabilities is not required.

\section{Results and discussion}

\subsection{The self-protonation of acrylonitrile in the dimer ions and the occurrence of proton-transport catalysis}

The base peak at $m / z 54$ in the MI spectrum of the acrylonitrile dimer ion at $\mathrm{m} / \mathrm{z}$ 106, see Fig. 1 corresponds to the generation of protonated acrylonitrile ions. Since the proton affinity (PA) of acrylonitrile, $187.5 \mathrm{kcal} \mathrm{mol}^{-1}$ [17b], is typical of a nitrile rather than an alkene, these ions undoubtedly have the structure $\mathrm{CH}_{2}=\mathrm{CHC} \equiv \mathrm{NH}^{+}$ (ANP) and not $\mathrm{CH}_{3} \mathrm{CHC} \equiv \mathrm{N}^{+}$. Indeed, it follows from the results of Table 1 that the self-protonation $\mathrm{CH}_{2}=\mathrm{CHC} \equiv \mathrm{N}^{\bullet+}$ $(\mathrm{AN})+\mathrm{CH}_{2}=\mathrm{CHC} \equiv \mathrm{N} \rightarrow \mathrm{CH}_{3} \mathrm{CHC} \equiv \mathrm{N}^{+}+\mathrm{CH}_{2}=\mathrm{C}^{\bullet}-\mathrm{C} \equiv \mathrm{N} \quad$ is endothermic, by $25 \mathrm{kcal} \mathrm{mol}^{-1}$, whereas formation of ANP with either $\mathrm{CH}_{2}=\mathrm{C}^{\bullet}-\mathrm{C} \equiv \mathrm{N}\left(\mathrm{ANR}_{1}\right)$ or ${ }^{\bullet} \mathrm{CH}=\mathrm{C}(\mathrm{H}) \mathrm{C} \equiv \mathrm{N}\left(\mathrm{ANR}_{2}\right)$ is exothermic, by 20 and $13 \mathrm{kcal} \mathrm{mol}^{-1}$, respectively.

One would therefore expect that in encounter complexes of ionized acrylonitrile with its neutral counterpart, protonation at the cyano group readily occurs and that, when energized, these 
Table 2

Energetic data ${ }^{a}$ derived from CBS-QB3 calculations pertinent to the dissociation chemistry of acrylonitrile dimer ions as described in Schemes 2-7

\begin{tabular}{|c|c|c|c|c|c|}
\hline Ionic/neutral species & B3LYP/CBSB7 E(total) & CBS-QB3 $E$ (total) $[0 \mathrm{~K}]$ & $\mathrm{ZPE}$ & QB3 $\Delta_{\mathrm{f}} H_{0}^{\circ}$ & QB3 $\Delta_{\mathrm{f}} H_{298}^{\circ}$ \\
\hline HBRC-1 (Scheme 2) & -341.41042 & -340.70404 & 62.5 & 330 & 327 \\
\hline HBRC-2 (Scheme 2) & -341.41065 & -340.70269 & 62.5 & 331 & 329 \\
\hline HBRC-3 (Scheme 3) & -341.44531 & b & 59.7 & $(314)$ & $(311)$ \\
\hline HBRC-4 (Scheme 3) & -341.43001 & -340.74531 & 60.4 & 304 & 301 \\
\hline D1 (Scheme 2) & -341.45639 & -340.76886 & 64.7 & 289 & 286 \\
\hline D2 (Scheme 2) & -341.42145 & -340.73700 & 63.6 & 309 & 306 \\
\hline D3 (Scheme 2) & -341.42048 & -340.73037 & 64.5 & 313 & 310 \\
\hline TS HBRC-1 $\rightarrow$ D1 & -341.41026 & -340.7049 & 62.6 & 330 & 327 \\
\hline TS HBRC-2 $\rightarrow$ D1 & -341.41043 & -340.7029 & 62.4 & 331 & 328 \\
\hline TS HBRC-1 $\rightarrow$ HBRC-3 & -341.39392 & -340.70212 & 58.9 & 331 & 328 \\
\hline TS HBRC-2 $\rightarrow$ HBRC-4 & -341.38607 & -340.69777 & 58.8 & 334 & 331 \\
\hline D4 (Scheme 7) & -341.46192 & -340.77004 & 64.5 & 289 & 285 \\
\hline D5 (Scheme 7) & -341.43638 & -340.74755 & 64.8 & 303 & 298 \\
\hline D6 (Scheme 4) & -341.43667 & -340.74303 & 65.5 & 306 & 302 \\
\hline D7 (Scheme 5) & -341.44061 & -340.74904 & 64.8 & 302 & 298 \\
\hline D8 (Scheme 7) & -341.42623 & -340.73286 & 62.7 & 312 & 308 \\
\hline TS D1 $\rightarrow$ D4 & -341.39405 & -340.70471 & 61.8 & 330 & 326 \\
\hline TS D1 $\rightarrow$ D6 & -341.35331 & -340.66747 & 59.8 & 353 & 349 \\
\hline TS D4 $\rightarrow$ D7 & -341.37789 & -340.68846 & 60.9 & 340 & 336 \\
\hline TS D7 $\rightarrow$ VP1 & -341.43441 & -340.74342 & 64.7 & 305 & 301 \\
\hline TS D4 $\rightarrow$ D5 & -341.43278 & -340.74516 & 64.1 & 304 & 300 \\
\hline TS D5 $\rightarrow$ VP1 & -341.39167 & -340.70135 & 63.9 & 332 & 327 \\
\hline TS D5 $\rightarrow$ D8 & -341.42123 & -340.73015 & 63.2 & 314 & 309 \\
\hline VP1 (Scheme 7) & -341.49269 & -340.79467 & 67.1 & 273 & 268 \\
\hline VP1b (Scheme 7) (text) & -341.43299 & -340.72866 & 65.8 & 315 & 310 \\
\hline VP1a (Scheme 7) (text) & -341.48804 & -340.79785 & 67.7 & 271 & 266 \\
\hline VP2 (Scheme 7) & -341.46800 & -340.77584 & 67.8 & 285 & 280 \\
\hline VP2a (Scheme 7) (text) & -341.46520 & -340.77672 & 67.1 & 284 & 280 \\
\hline $\mathrm{TS} \mathrm{VP} 1 \rightarrow \mathrm{VP} 2$ & -341.41261 & -340.72597 & 66.0 & 316 & 311 \\
\hline TS VP1 $\rightarrow$ VP1a & -341.44621 & -340.76169 & 63.5 & 294 & 289 \\
\hline $\mathrm{TS} \mathrm{VP} 2 \rightarrow \mathrm{VP} 2 \mathrm{a}$ & -341.42553 & -340.74089 & 64.4 & 307 & 302 \\
\hline $\mathrm{TS} \mathrm{VP} 1 \rightarrow \mathrm{VP} 1 \mathrm{~b}$ & -341.41280 & -340.72419 & 64.6 & 318 & 313 \\
\hline
\end{tabular}

${ }^{a} E_{\text {(total) }}$ in Hartrees, all other components, including the ZPE scaled by 0.99 , are in $\mathrm{kcal} \mathrm{mol}^{-1}$.

b Estimate from a B3LYP/CBSB7 calculation using HBRC-4 as the anchor; the CCSD(T) component in the CBS-QB3 calculation did not converge.

complexes dissociate into ANP $(\mathrm{m} / \mathrm{z}$ 54) rather than AN $(\mathrm{m} / \mathrm{z}$ 53). Yet, in the $\mu$ s time frame metastable dimer ions show four other competing dissociations including loss of acrylonitrile.

One explanation for the presence of the substantial $\mathrm{m} / \mathrm{z}, 53$ peak in the MI spectrum is that the protonation process leading to $m / z, 54$ involves a significant reverse energy barrier. This would make dissociation of the dimer into its ionic and neutral acrylonitrile components more competitive with the protonation. Alternatively, the $m / z 53$ ions in the MI spectrum of Fig. 1 do not represent ions $\mathrm{AN}$ but rather ions $\mathrm{CH}_{2}=\mathrm{C}=\mathrm{C}=\mathrm{NH}^{+}$(AN1), which are more stable by $17 \mathrm{kcal} \mathrm{mol}^{-1}$, see Table 1 .

Solitary ions AN cannot isomerize into AN1: the calculated energy requirement (CBS-QB3 data Table 1) for this isomerization - a 1,3-H shift at $87 \mathrm{kcal} \mathrm{mol}^{-1}$ or, more economically, two consecutive $1,2-\mathrm{H}$ shifts at $46-47 \mathrm{kcal} \mathrm{mol}^{-1}$ - is quite high and well above that for dissociation of the incipient ions AN1 by $\mathrm{H}^{\bullet}$ loss into the N-protonated cyanoacetylene ion [3], see Scheme 1.

However, the high barrier for the one-step isomerization via a 1,3-H shift in the solitary ion may vanish in the encounter complex if the neutral component catalyses the transformation. Criteria for successful proton-transport catalysis have been developed by Böhme [2d] and Radom and co-workers [19]. The most important criterion predicts that a smooth isomerization $\mathrm{AN} \rightarrow$ AN1 would occur if the PA of the base (B) (acrylonitrile) lies between the PA of $\mathrm{CH}_{2}=\mathrm{C}^{\bullet}-\mathrm{C} \equiv \mathrm{N}$ at $\mathrm{C}$ and at $\mathrm{N}$. If $\mathrm{PA}(\mathrm{B})$ is too low, proton abstraction will not take place. If $\mathrm{PA}(\mathrm{B})$ is too high, the incipient ion $\mathrm{BH}^{+}$will not release the proton: dissociation to $\mathrm{CH}_{2}=\mathrm{C}^{\bullet}-\mathrm{C} \equiv \mathrm{N}+\mathrm{BH}^{+}\left(\mathrm{CH}_{2}=\mathrm{CHC} \equiv \mathrm{NH}^{+}(\mathrm{ANP})\right)$ will ensue instead. From the CBS-QB3 results in Table 1 we derive values of 168,185 and $188 \mathrm{kcal} \mathrm{mol}^{-1}$ for $\mathrm{PA}\left(\mathrm{CH}_{2}=\mathrm{C}^{\bullet}-\mathrm{C} \equiv \mathrm{N}\right.$ at $\mathrm{C}), \mathrm{PA}\left(\mathrm{CH}_{2}=\mathrm{C}^{\bullet}-\mathrm{C} \equiv \mathrm{N}\right.$ at $\left.\mathrm{N}\right)$ and $\mathrm{PA}(\mathrm{B})$, respectively; the latter value is in excellent agreement with the experimental value. Thus the PA of the base is too high, but only marginally so, which implies that PTC cannot $a$ priori be ruled out.

Various ion-dipole complexes may be formed in the reaction of acrylonitrile with its ionic counterpart which, because of the large dipole moment of the nitrile $(\mu=3.9 \mathrm{D})$, are expected to have stabilization energies in the $10-20 \mathrm{kcal} \mathrm{mol}^{-1}$ range. Among these, two hydrogen-bridged dimer ions may be envisaged, viz. HBRC-1 and HBRC-2 as depicted in Scheme 2. These $\mathrm{C}-\mathrm{H}-\mathrm{N}$ hydrogen-bridged radical cations [20] are calculated to have stabilization energies of $15-17 \mathrm{kcal} \mathrm{mol}^{-1}$ at the 

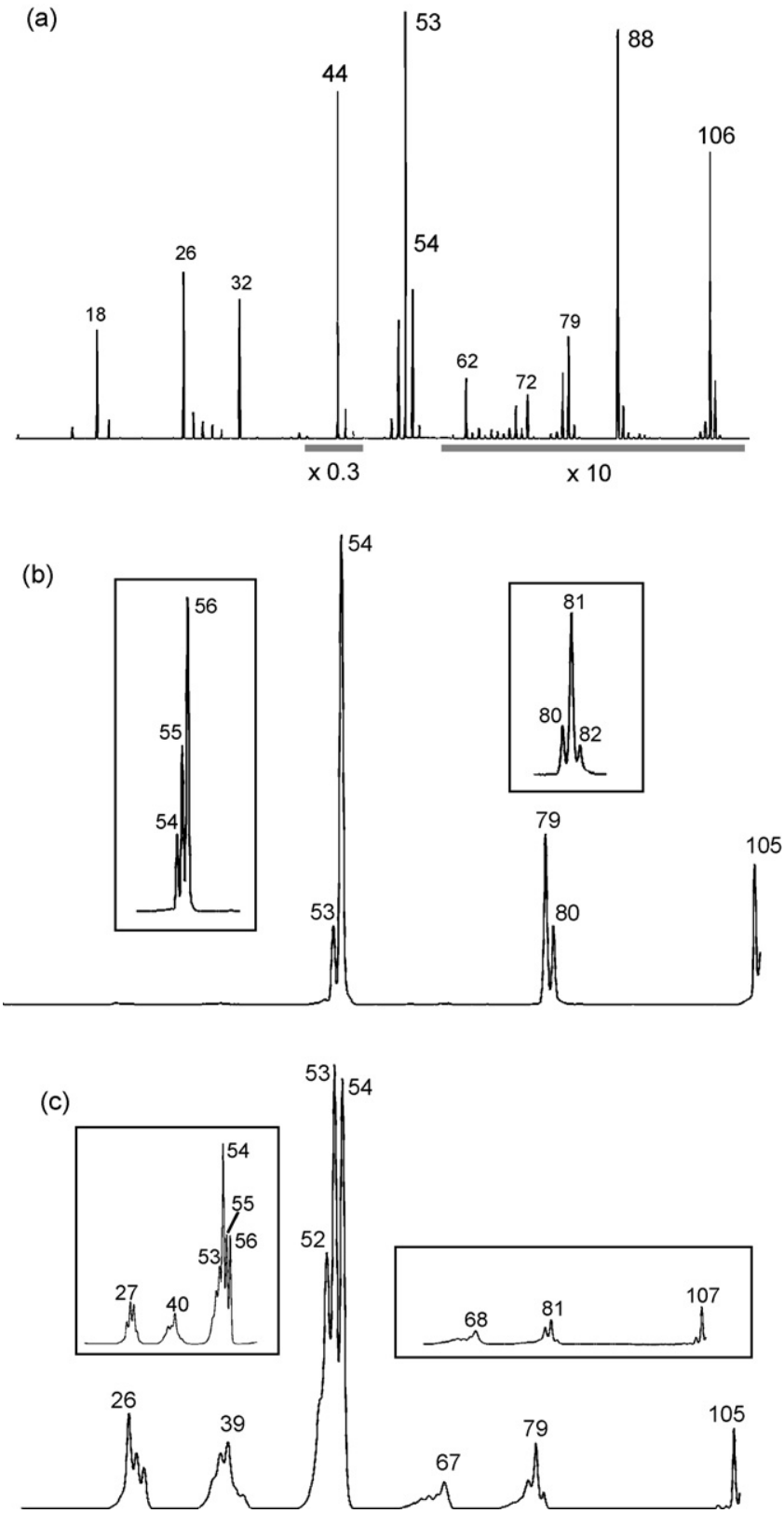

Fig. 1. (a) Chemical ionization mass spectrum of a mixture of gaseous acrylonitrile and $\mathrm{CO}_{2}$. The $\mathrm{MI}$ and the CID spectra of the $\mathrm{m} / \mathrm{z}, 106$ acrylonitrile dimer ions of this spectrum are shown as items (b) and (c), respectively. The insets in (b) and (c) refer to the spectra of the $\mathrm{m} / \mathrm{z} 108$ dimer ions of acrylonitrile-2-d.

CBS-QB3 level of theory. They both lie in a very shallow potential well with small barriers for rearrangement into ion-dipole complexes that are not hydrogen-bridged. More importantly, these HBRCs can also rearrange with a negligible barrier into the covalently bound isomer D1 which has a much larger stabilization energy, $58 \mathrm{kcal} \mathrm{mol}^{-1}$. Two more covalently bound isomers were identified as stable minima viz. ions D2 and D3 in Scheme 2. The latter ion has been proposed as the dimer ion core in an infrared photodissociation study of acrylonitrile cluster ions $\left(\mathrm{CH}_{2}=\mathrm{CHC} \equiv \mathrm{N}\right)_{n}{ }^{\bullet+}(n=3-10)$ [21]. Both isomers are considerably less stable than D1 and play no obvious role in the dissociation chemistry of the dimer ions. In contrast, as we shall see in the next section, ion D1 may act as the reacting configuration for a 1,2-H shift that initiates the observed losses of $\mathrm{H}^{\bullet}$, $\mathrm{HCN}$ and $\mathrm{C}_{2} \mathrm{H}_{2}$ from the low-energy dimer ions.

The self-protonation leading to $\mathrm{m} / \mathrm{z} 54$ - and also the formation of $\mathrm{m} / \mathrm{z} 53$ if proton-transport catalysis plays a role - most likely involves HBRC-1 and HBRC-2. That the self-protonation reaction in these ions does not proceed spontaneously follows from a consideration of the symmetries of the corresponding electronic wave functions. Radical cation AN as well as the radicals $\mathrm{ANR}_{1}$ and $\mathrm{ANR}_{2}$ are planar. The $\mathrm{AN}$ ground state $\left(\Delta_{\mathrm{f}} H_{298}=298 \mathrm{kcal} \mathrm{mol}^{-1}\right)$ has ${ }^{2} \mathrm{~A}^{\prime \prime}$ symmetry; the lowest ${ }^{2} \mathrm{~A}^{\prime}$ state lies $34 \mathrm{kcal} \mathrm{mol}^{-1}$ higher in energy. The ground states of the radicals ANR1 and $\mathrm{ANR}_{2}$, however, have ${ }^{2} \mathrm{~A}^{\prime}$ symmetry. The lowest ${ }^{2} \mathrm{~A}^{\prime \prime}$ states for these radicals correspond to excitation energies of 52 and $53 \mathrm{kcal} \mathrm{mol}^{-1}$, respectively. Since these excitation energies are much larger than the stabilization energies of HBRC-1 and HBRC-2, the reaction cannot proceed through any of the excited states. As a consequence, the symmetry of the wave function has to change during the proton transfer for the reaction to proceed at energies below the threshold for disproportionation into an acrylonitrile ion and neutral $\left(344 \mathrm{kcal} \mathrm{mol}^{-1}\right)$. Thus, assuming that the complex is planar, we have to deal with the intersection between the two PESs corresponding to the ${ }^{2} \mathrm{~A}^{\prime}$ and ${ }^{2} \mathrm{~A}^{\prime \prime}$ states of the complex. However, the two states can be connected by lowering the symmetry of the nuclear framework of the $\mathrm{CH}_{2}=\mathrm{CHC} \equiv \mathrm{N}^{\bullet+}$ moiety. This leads to a TS by distorting the nuclear framework of this moiety such that the $\mathrm{CH}_{2}=\mathrm{CH}$ $\pi$-bond is partially broken. The transition states for the selfprotonation reactions depicted in Scheme $3 \mathrm{a}$ and $\mathrm{b}$ were found to lie just above the corresponding hydrogen-bridged complexes HBRC-1/2. The barrier for formation of $\mathrm{ANR}_{1}$ is lower than that for $\mathrm{ANR}_{2}$, by $3 \mathrm{kcal} \mathrm{mol}^{-1}$, leading to the expectation that $\mathrm{ANR}_{1}$ is preferentially formed. Note that the two radicals cannot freely interconvert because of a prohibitively high barrier of $52 \mathrm{kcal} \mathrm{mol}^{-1}$, see Table 1 .

Our chemical ionization experiments involving acrylonitrile2-d, $\mathrm{CH}_{2}=\mathrm{CDC} \equiv \mathrm{N}$, are in qualitative agreement with the scenario depicted in Scheme 3. The deuterated dimer ions dissociate into both $\mathrm{CH}_{2}=\mathrm{CDC} \equiv \mathrm{ND}^{+}(\mathrm{m} / \mathrm{z}, 56)+\mathrm{CH}_{2}=\mathrm{C}^{\bullet}-\mathrm{C} \equiv \mathrm{N}$ $\left(\mathrm{ANR}_{1}\right)$ and $\mathrm{CH}_{2}=\mathrm{CDC} \equiv \mathrm{NH}^{+}(\mathrm{m} / z \quad 55)+{ }^{\bullet} \mathrm{CH}=\mathrm{C}(\mathrm{D}) \mathrm{C} \equiv \mathrm{N}$

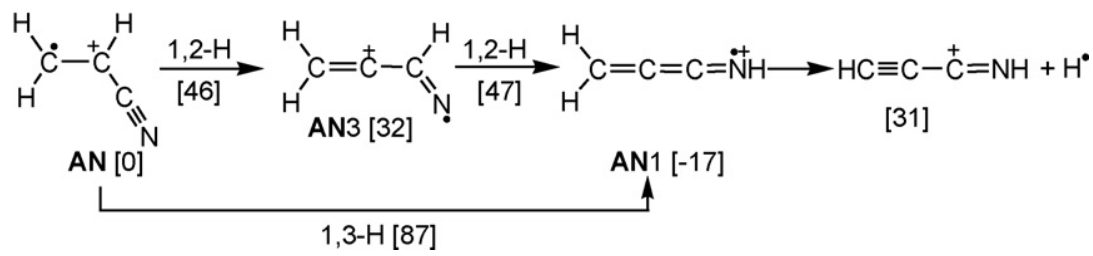

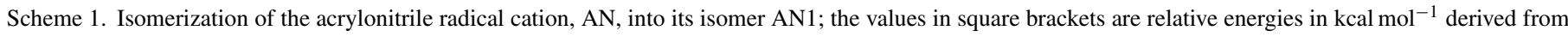
CBS-QB3 (298 K) calculations. 


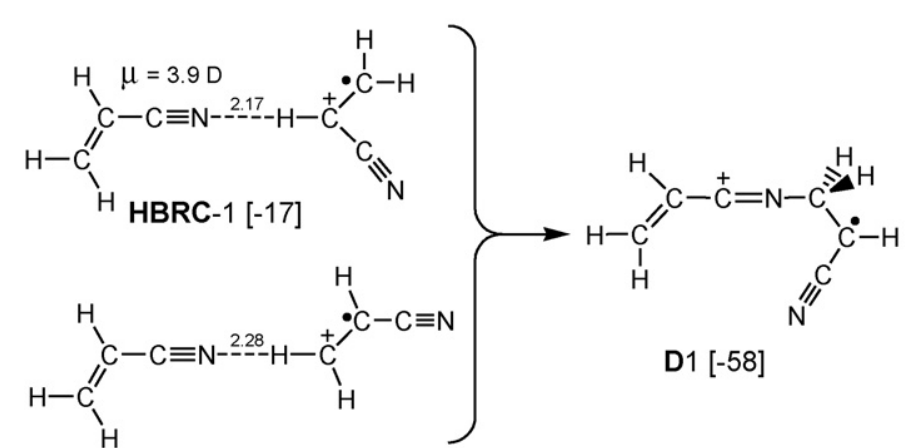

HBRC-2 [-15]<smiles></smiles><smiles>C=CN=C(C#N)C=C</smiles>

D2 [-38]

Scheme 2. Structures of stable acrylonitrile dimer ions and their stabilization energies $\left(\mathrm{kcal} \mathrm{mol}^{-1}\right)$ relative to the dissociation level $\mathrm{CH}_{2}=\mathrm{CHCN}^{\bullet+}$ (AN) $+\mathrm{CH}_{2}=\mathrm{CHCN}$; the values in square brackets refer to CBS-QB3 $(298 \mathrm{~K})$ calculations.

$\left(\mathrm{ANR}_{2}\right)$. This is seen from the inset in the MI spectrum of Fig. 1b, where the $m / z 56$ peak is about twice as intense as the $m / z 55$ peak. Thus both $\mathrm{ANR}_{1}$ and $\mathrm{ANR}_{2}$ radicals are formed with a relative abundance of $2: 1$, and note that $\mathrm{ANR}_{1}$ is thermodynamically the more stable radical. The peak intensity ratio $(\mathrm{m} / \mathrm{z}, 56+\mathrm{m} / \mathrm{z}, 55) / \mathrm{m} / \mathrm{z} 54$ equals the $\mathrm{m} / \mathrm{z}, 54 / \mathrm{m} / \mathrm{z} 53$ peak intensity ratio (6.0) in the spectrum of the unlabelled dimer indicating that there is no isotope effect associated with the reactions.

We further note that after passing the transition state, ANP may be formed directly or via $\mathrm{N}-\mathrm{H}-\mathrm{N}$ bridged complexes with $\mathrm{ANR}_{1}$ or $\mathrm{ANR}_{2}$, viz. HBRC-3 and HBRC-4 in Scheme 3. (We note that the stabilization energies calculated for these HBRCs, ca. $30 \mathrm{kcal} \mathrm{mol}^{-1}$, is close to that obtained by experiment for the $\mathrm{N}-\mathrm{H}-\mathrm{N}$ bridged proton bound dimer of acrylonitrile, $30.7 \mathrm{kcal} \mathrm{mol}^{-1}$ [22].) However, these HBRCs may also accommodate back-donation of the abstracted proton which would lead to the isomerization of the AN ion into either of its more stable isomers $\mathrm{CH}_{2}=\mathrm{C}=\mathrm{C}=\mathrm{NH}^{\bullet+}$ (AN1) or $\mathrm{CH}=\mathrm{CH}=\mathrm{C}=\mathrm{NH}^{\bullet+}$ (AN2). These ions both turn out to have ${ }^{2} \mathrm{~A}^{\prime}$ ground states, enabling the corresponding proton transfers to take place spontaneously, provided these processes are exothermic. Using the CBS-QB3 derived $\Delta_{\mathrm{f}} H_{298}$ values of the components in Table 1, we obtain the following energies for the dissociation products: $\Delta_{\mathrm{f}} H_{298}(\mathrm{ANl}+\mathrm{ANN})=327 \mathrm{kcal} \mathrm{mol}^{-1}$ and $\Delta_{\mathrm{f}} H_{298}(\mathrm{AN} 2+\mathrm{ANN})=335 \mathrm{kcal} \mathrm{mol}^{-1}$. These energies are only slightly higher than those for the products of the self-protonations: $\Delta_{\mathrm{f}} H_{298}\left(\mathrm{ANP}+\mathrm{ANR}_{1}\right)=324 \mathrm{kcal} \mathrm{mol}^{-1}$ and $\Delta_{\mathrm{f}} H_{298}\left(\mathrm{ANP}+\mathrm{ANR}_{2}\right)=331 \mathrm{kcal} \mathrm{mol}^{-1}$. This implies that the PTC processes cannot be ruled out on energetic grounds because the energy available in the dimer ions is sufficiently high for either dissociation route. On the other hand, both reactions are exothermic for ions that pass either of the transition states where their configuration is such that formation of ANP involves a mere bond cleavage whereas the formation of the PTC ions AN1 or AN2 requires a significant rearrangement. This makes it unlikely that the PTC processes can effectively compete with the selfprotonations. In this context it is important to note that both self-protonation reactions occur and that the self-protonation of Scheme $3 \mathrm{~b}$ lies $4 \mathrm{kcal} \mathrm{mol}^{-1}$ higher in energy than the PTC process of Scheme 3a. Yet, only self-protonation is observed.

Evidence that PTC does not play a significant role comes from an experiment in which we probed the structure of the $\mathrm{m} / \mathrm{z}$ (a)

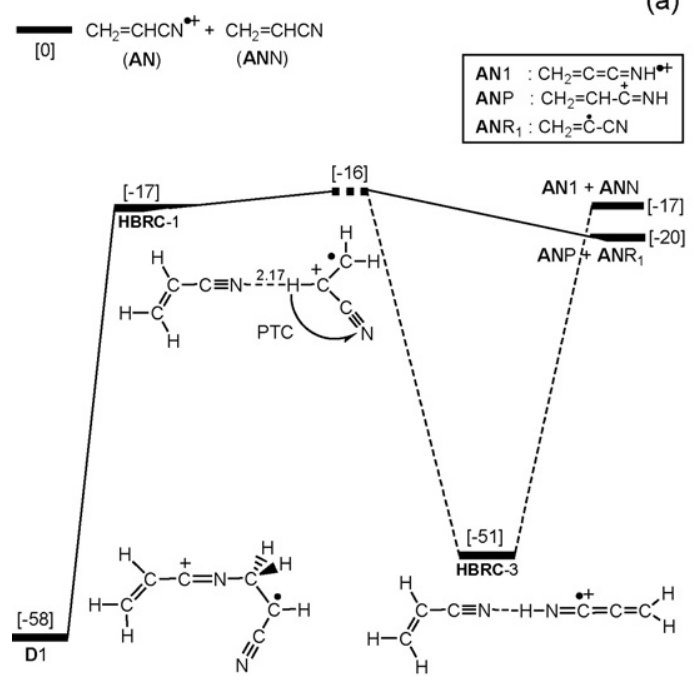

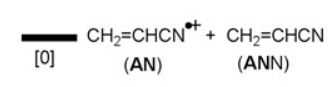

(b)

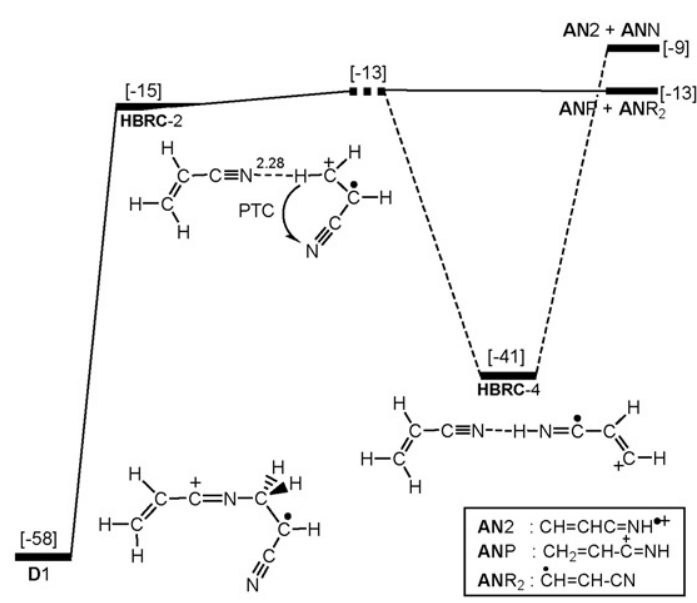

Scheme 3. ( $\mathrm{a}$ and $\mathrm{b}$ ) Potential energy diagrams (CBS-QB3 calculations) describing the self-protonation reaction and the occurrence of proton-transport catalysis in acrylonitrile dimer ions. The relative energies are in $\mathrm{kcal} \mathrm{mol}^{-1}$. 
53 ions in the MI spectrum of Fig. 1 by obtaining their CID mass spectrum. This spectrum is shown in Fig. 2a: it is virtually identical with that of acrylonitrile ions generated by electron impact and characteristically different from that of ions AN1 and AN2 discussed in a previous study [3].

\subsection{Back-dissociation versus self-protonation in the acrylonitrile dimer ions $H B R C-1 / 2$}

In the previous section we have established that the $m / z, 53$ ions in the MI spectrum do not result from proton-transport catalysis but rather are ions AN resulting from a back-dissociation. It follows from the energy diagram of Scheme 3, that dimer ions dissociating back into $\mathrm{AN}+\mathrm{ANN}$ can only do so at energies largely in excess of that required for self-protonation. Prima facie, therefore, the observed competition in the $\mu$ s time frame of the back-dissociation with the self-protonation is surprising. However, the following considerations may rationalize why dissociation by self-protonation requires a sizable excess energy.

First, the majority of the reacting configurations do not correspond to HBRC-1/2, which lie in very shallow wells, but to the much more stable ion D1 (at $286 \mathrm{kcal} \mathrm{mol}^{-1}$ ). According to RRKM theory [23], this implies that a relatively large excess energy is needed. The same argument applies to the dissociations of the very stable ions HBRC-3/4.

Second, the large dipole moment of acrylonitrile $(\mu=3.9 \mathrm{D})$ and also of the radicals ANR1/2 $(\mu=3.8$ and $3.2 \mathrm{D}$, respectively; calculated values) probably leads to a dramatic decrease, by some orders of magnitude, of the dissociation rate constants, as compared to an RRKM (variational transition state theory) estimate. It has been argued that such dissociations do not behave statistically, as classical trajectory calculations have shown that the trajectories leading to dissociation are quasiperiodical instead of chaotic because of the large ion-dipole stabilization [24]. We suggest that the non-planarity of the transition states connecting HBRC-1 to HBRC-3 and HBRC-2 to HBRC-4 also contributes to a non-statistical behaviour. Our calculations show that the distortions in the $\mathrm{CH}_{2}=\mathrm{CHC} \equiv \mathrm{N}^{\bullet+}$ moiety lead to transition states that are $10-13 \mathrm{kcal} \mathrm{mol}^{-1}$ lower in energy than the corresponding (planar) minimum energy crossing points. The self-protonation will then only be effective if the internal rotation of the $\mathrm{CH}_{2}$-group in the $\mathrm{CH}_{2}=\mathrm{CHC} \equiv \mathrm{N}^{\bullet+}$ moiety is excited and the $\mathrm{CH}_{2}=\mathrm{CHC} \equiv \mathrm{N}$ moiety approaches the ion from the right direction. Because of the large ion-dipole stabilization for all other orientations, the reaction may be substantially slowed down by non-statistical behaviour.

Experimental evidence that the self-protonation is relatively slow comes from a comparison of the MI and CID spectra of the dimer ions presented in Fig. 1: self-protonation dominates the MI spectrum, but in the CID spectrum the $\mathrm{m} / z$. 54 peak is diminished with respect to the $m / z 53$ back-dissociation.

\subsection{Self-protonation via the covalently bound acrylonitrile dimer ions $D-1$ ?}

We have also entertained the possibility that protonated acrylonitrile product ions are generated via a hydrogen shift in
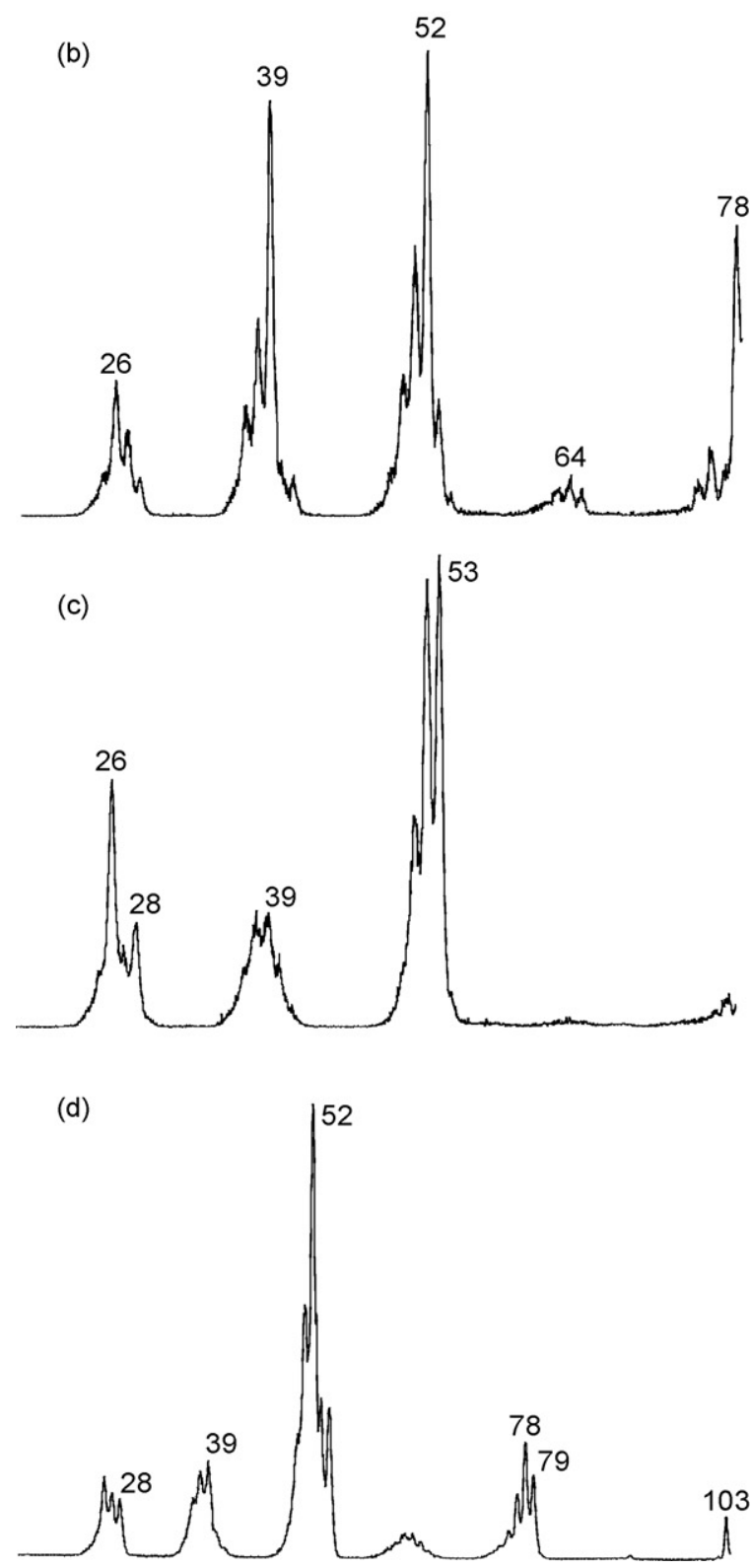

Fig. 2. CID mass spectra of product ions generated from metastable acrylonitrile dimer ions: (a) $\mathrm{m} / \mathrm{z} 53$ ions (loss of acrylonitrile); (b) $\mathrm{m} / \mathrm{z} 79$ ions (loss of $\mathrm{HCN}$ ); (c) $\mathrm{m} / z 80$ ions (loss of $\mathrm{C}_{2} \mathrm{H}_{2}$ ); (d) $\mathrm{m} / z 105$ ions (loss of $\mathrm{H}^{\bullet}$ ). 


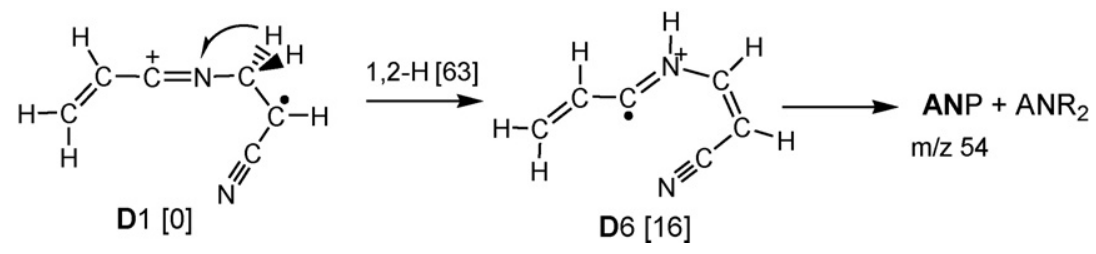

Scheme 4

covalently bound dimer ions. An obvious route for ions D1 is the one shown in Scheme 4, where the second step is a simple bond cleavage.

This route is not feasible: the 1,2-H shift for the isomerization D1 $\rightarrow$ D6 is calculated to be more energy demanding than the formation of ANP $(m / z 54)$ via the HBRCs and also, see Scheme 7, the formation of $\mathrm{m} / \mathrm{z}, 105$ ions by loss of $\mathrm{H}^{\bullet}$ from D1. Another possibility is that ions D6 are generated from ion D7, by a 1,4-H shift. The formation of D7 from D1, see Scheme 5 below, was considered because our calculations indicate that D7 readily cyclizes into the vinyl pyrimidine type ions VP1/2 of Scheme 7. Ion D7 could thus account for the observed loss of $\mathrm{C}_{2} \mathrm{H}_{2}$ from the acrylonitrile dimer ions and the formation of $\mathrm{m} / \mathrm{z} 80$ pyrimidine type product ions.

This scenario is not a viable option either: the barrier for the isomerization D1 $\rightarrow$ D7 via two consecutive $1,2-\mathrm{H}$ shifts, see Scheme 5 , is so high that it is unlikely that ions D7 play a role in the dissociation chemistry of the acrylonitrile dimer ions.

Thus it seems likely that the formation of $m / z .54$ in the MI spectrum of the dimer ions occurs via HBRC-1/2. However, these HBRCs and the related non-hydrogen bridged ion-dipole complexes cannot account for the competing loss of $\mathrm{H}^{\bullet}$ and also that of $\mathrm{HCN}$ and $\mathrm{C}_{2} \mathrm{H}_{2}$, which may well involve a cyclic precursor ion. As we shall see in the next section rearrangement reactions starting from the covalently bound dimer ions D1 can account for all three losses.

\subsection{The dissociation of the acrylonitrile dimer ion D1: generation of ionized pyrimidine and its isomer ionized pyrimidine-2-ylidine}

The mechanistic proposal for the dissociation of the dimer ions D1 by loss of $\mathrm{HCN}, \mathrm{C}_{2} \mathrm{H}_{2}$ and $\mathrm{H}^{\bullet}$ is presented in Scheme 7. Its analysis will await the evaluation of the experimental evidence for the proposed product ion structures. That the neutrals lost from D1 are $\mathrm{HCN}$ rather than $\mathrm{C}_{2} \mathrm{H}_{3}{ }^{\bullet}$ and also $\mathrm{C}_{2} \mathrm{H}_{2}$ rather than $\mathrm{CN}^{\bullet}$ is confirmed by the MI spectrum of the fully deuterated dimer ion $(m / z, 112)$ which displays a single peak at $m / z 84$ in the $m / z 80$ region.
The CID spectrum of the $m / z 79 \mathrm{C}_{5} \mathrm{H}_{5} \mathrm{~N}$ ions generated by loss of $\mathrm{HCN}$ from the metastable dimer ions is shown in Fig. $2 \mathrm{~b}$. The major peaks at $m / z, 52$ (loss of $\mathrm{HCN}$ and/or $\mathrm{C}_{2} \mathrm{H}_{3}{ }^{\bullet}$ ), $\mathrm{m} / \mathrm{z}, 39$ $\left(\mathrm{C}_{3} \mathrm{H}_{3}{ }^{+}\right)$and $m / z, 26\left(\mathrm{C}_{2} \mathrm{H}_{2}{ }^{\bullet+}\right)$ are compatible with the proposed linear $\mathrm{C}_{5} \mathrm{H}_{5} \mathrm{~N}^{\bullet+}$ isomer of Scheme 7. Reference CID mass spectra of non-cyclic $\mathrm{C}_{5} \mathrm{H}_{5} \mathrm{~N}^{\bullet+}$ isomers are not available so that this structure assignment must remain tentative. We further note that the CID spectrum of Fig. $2 b$ is incompatible with that of ionized pyridine or its distonic analogues. These very stable cyclic $\mathrm{C}_{5} \mathrm{H}_{5} \mathrm{~N}^{\bullet+}$ isomers all display CID spectra that are dominated by a peak at $m / z, 52$ (loss of $\mathrm{HCN}$ ) [25].

A different scenario obtains for the structure assignment of the $m / z, 80$ ions. Here the overall appearance of the CID mass spectrum of the metastably generated ions is that of a cyclic $\mathrm{C}_{4} \mathrm{H}_{4} \mathrm{~N}_{2}{ }^{\bullet+}$ ion, viz. ionized pyrimidine (PY1) and/or one of its ylide counterparts PY2-PY5 shown in Scheme 6 (relative energies in $\mathrm{kcal} \mathrm{mol}^{-1}$ from Ref. [3]).

We have previously studied the above system of $\mathrm{C}_{4} \mathrm{H}_{4} \mathrm{~N}_{2} \bullet+$ ions in detail, by both theory and experiment [3]. The calculations of this study predict that the five stable pyrimidine isomers have comparable energies but also high interconversion barriers. In spite of this, ions PY1-PY4 (PY5 was not experimentally accessible) display similar CID mass spectra. However, the isomers can be differentiated on the basis of the intensity ratios of the $m / z 26\left(\mathrm{C}_{2} \mathrm{H}_{2}{ }^{\bullet+}\right)$ and $m / z 28\left(\mathrm{HCNH}^{+}\right)$peaks which result from high energy CID dissociations. A comparison of the CID mass spectrum of Fig. 2c with the CID mass spectra of PY1-PY4 of our previous study [3] indicates that the loss of $\mathrm{C}_{2} \mathrm{H}_{2}$ from D1 yields ionized pyrimidine in admixture with its ylide isomer PY2 in a 1:1 ratio. The analysis of the CID spectra allows the possibility that the co-generated distonic ion is $\mathrm{PY} 3$ rather than PY2 but in our quest of mechanistic proposals for the $\mathrm{C}_{2} \mathrm{H}_{2}$ loss we have not been able to find a plausible pathway for its generation.

The CID mass spectrum of the $\mathrm{m} / \mathrm{z} 105$ ions generated by loss of $\mathrm{H}^{\bullet}$ is presented in Fig. 2d. Reference spectra are not available for this system of ions. However, the base peak in the spectrum at $\mathrm{m} / \mathrm{z}, 52$ can readily be rationalized in terms of the structure proposed in Scheme 7, viz. by invoking a simple bond

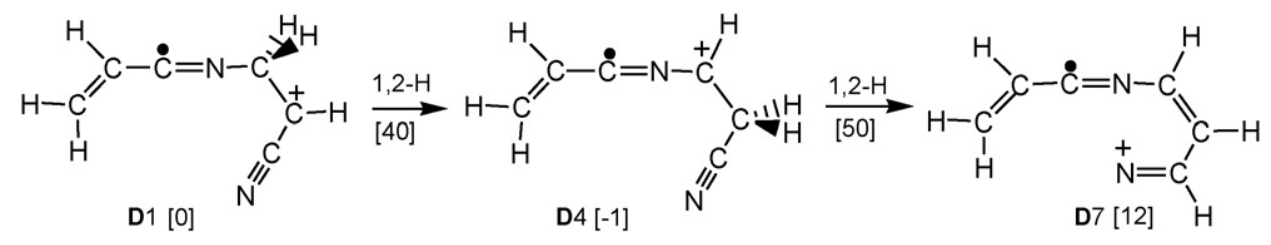

Scheme 5. Isomerization pathways of acrylonitrile dimer ions D1 into ions D7. The relative energies in square brackets are in kcal mol ${ }^{-1}$ and were obtained from CBS-QB3 calculations (Table 2). 
<smiles></smiles>

PY1 [0]<smiles></smiles>

PY2 [4]<smiles></smiles>

PY3 [8]<smiles></smiles>

PY4 [9]<smiles>C1=CN=CNC=C1</smiles>

PY5 [2]

Scheme 6.

cleavage into $\mathrm{CH}=\mathrm{CHC} \equiv \mathrm{N}^{+}(m / z, 52)+\mathrm{CH}_{2}=\mathrm{CHC} \equiv \mathrm{N}$. Further support for the structure assignment comes from exploratory calculations which confirm that the least energy demanding $\mathrm{H}^{\bullet}$ loss from D1 is that of a methylene hydrogen and the discussion of the mixed dimer ions $\mathrm{D} 1(\mathrm{Cl})$ at the end of this section.

We now turn to a discussion of our mechanistic proposals using the energy diagram of Scheme 7 as a guide.

\subsubsection{Formation of pyrimidine via loss of $\mathrm{C}_{2} \mathrm{H}_{2}$}

As discussed above, see Scheme 2, the reaction between two acrylonitrile monomers can lead to a variety of possible dimers.
The most stable direct chemically bonded dimer was found to be D1 which has a stabilization energy of $58 \mathrm{kcal} \mathrm{mol}^{-1}$ relative to $\mathrm{AN}+\mathrm{ANN}$. A six membered ring with the $\mathrm{N}-\mathrm{C}-\mathrm{N}$ connectivity of pyrimidine may be envisaged to occur by ring closure of D1 but such a species is not a minimum on the potential energy surface. In contrast, ions D4 generated from a 1,2-H shift in D1, can readily lead to the desired ring closure. The fairly energy demanding 1,2-H shift for the transformation D1 $\rightarrow$ D4 $\left(40 \mathrm{kcal} \mathrm{mol}^{-1}\right)$ allows the incipient ions D4 to cyclize into D5. This ion can further rearrange by a 1,2-H shift into the 2-vinylpyrimidine radical cation, VP1, which may serve as the
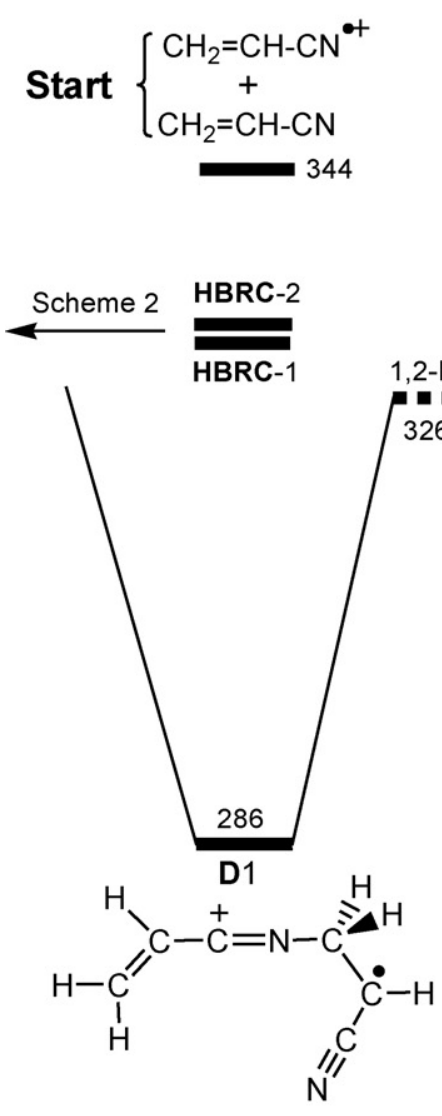

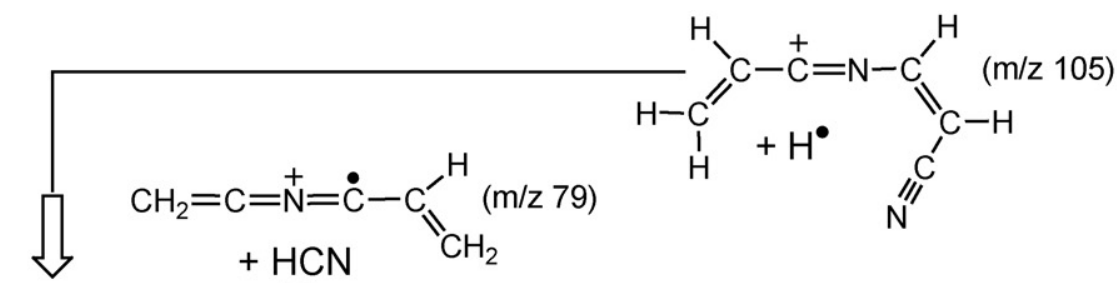
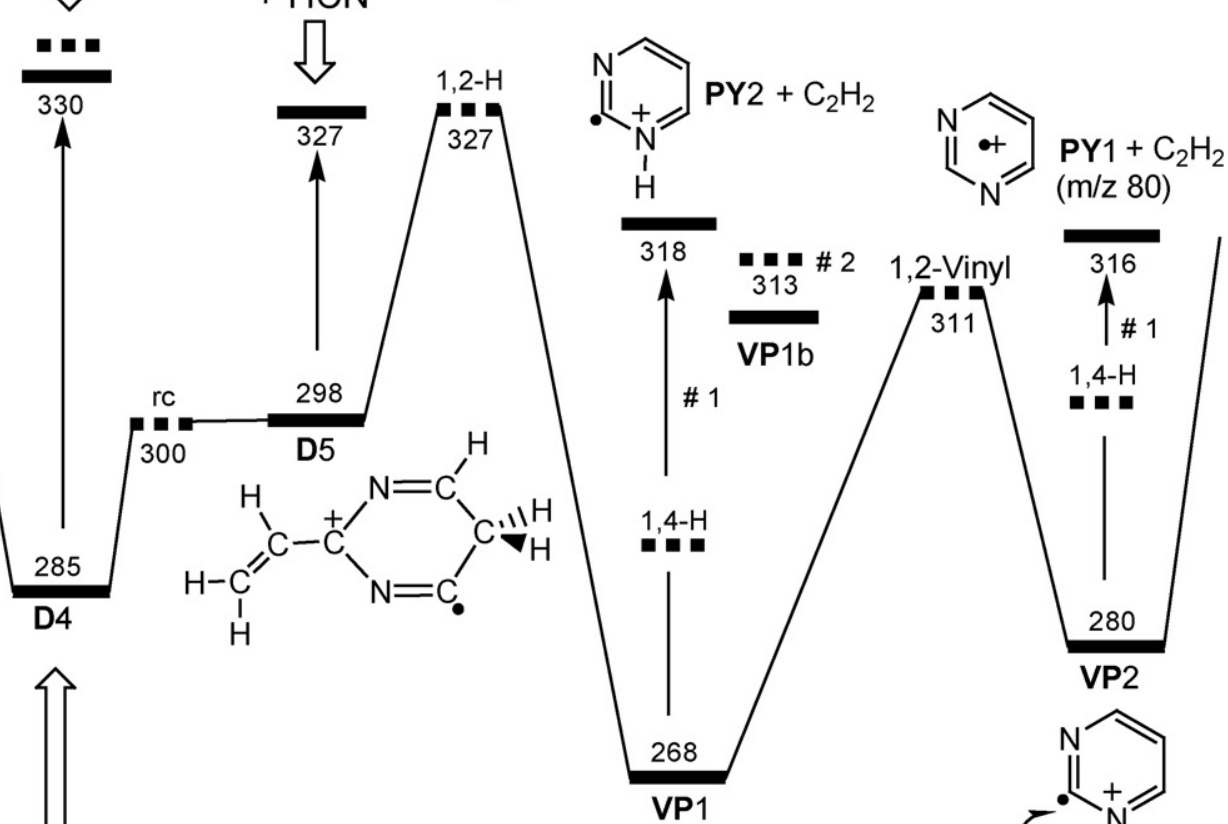<smiles>C=C[C+]=N[CH]C#N</smiles><smiles></smiles>

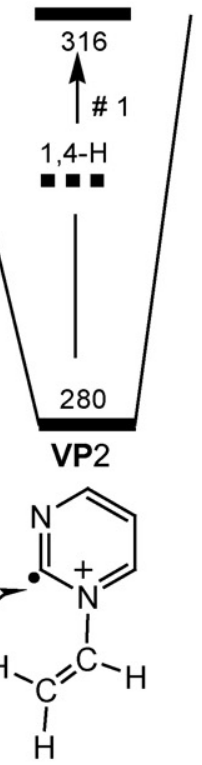

Scheme 7. Energy diagram derived from CBS-QB3 $298 \mathrm{~K}$ calculations $\left(\mathrm{kcal} \mathrm{mol}^{-1}\right)$ describing the losses of $\mathrm{C}_{2} \mathrm{H}_{2}, \mathrm{HCN}$ and $\mathrm{H}$ from metastable acrylonitrile dimer ions D1. Note \#1: dissociation from VP1a and VP2a, see text; Note \#2: exchange vinyl H atoms via VP1b, see text. 


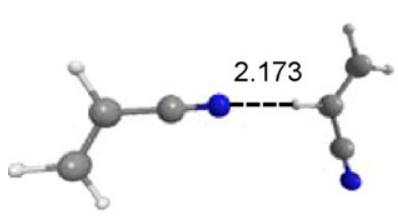

HBRC-1

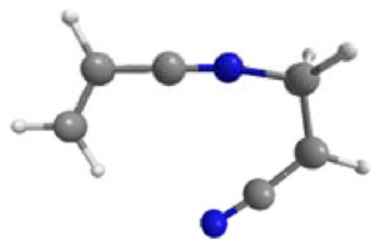

D1

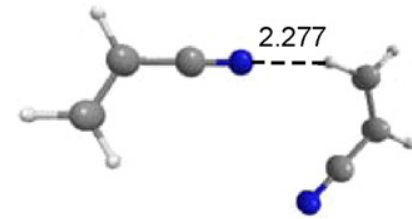

HBRC-2

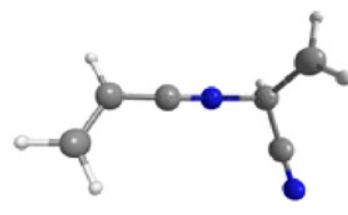

D2

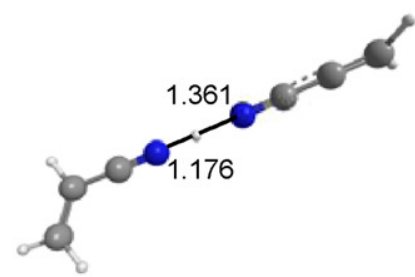

HBRC-3

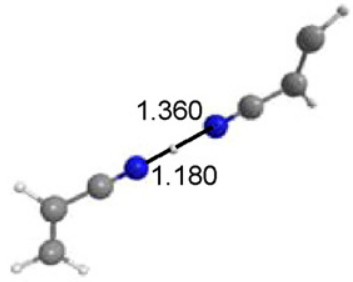

HBRC-4

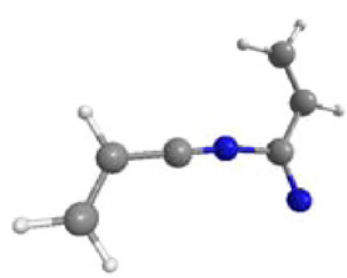

D3

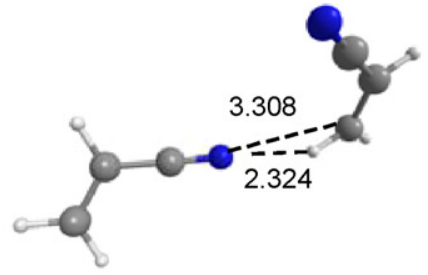

TS HBRC-1 - D1

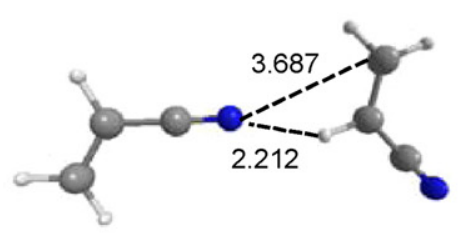

TS HBRC-2 - D1

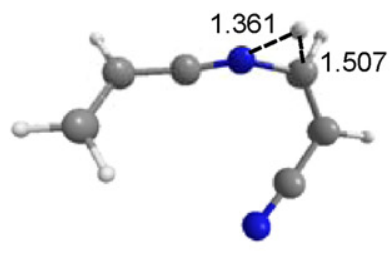

TS D1 - D6

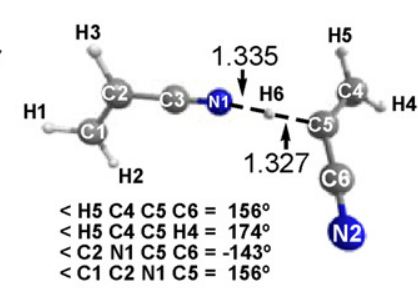

TS HBRC-1 - AN(P)

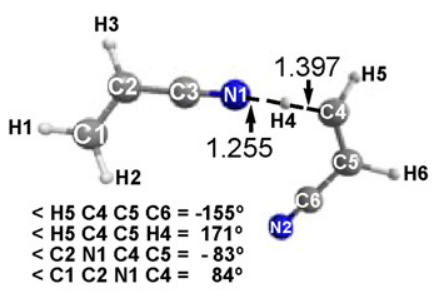

TS HBRC-2 - AN(P)

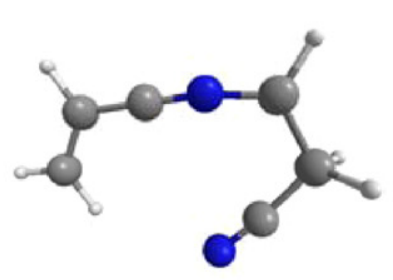

D4

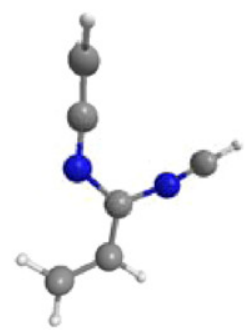

D8

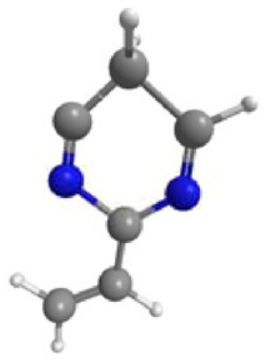

D5

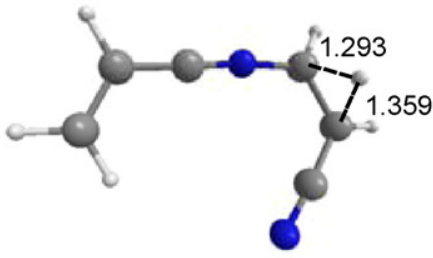

TS D1 - D4

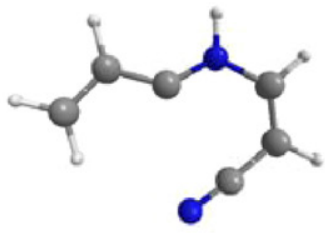

D6

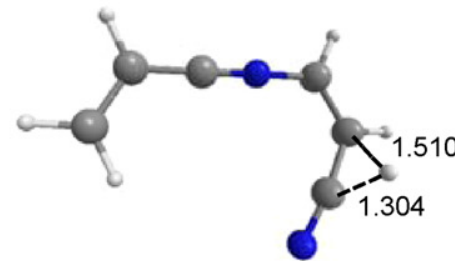

TS D4 - D7

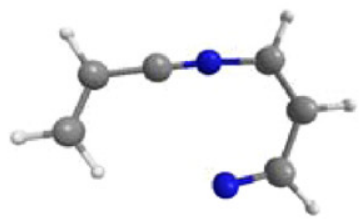

D7

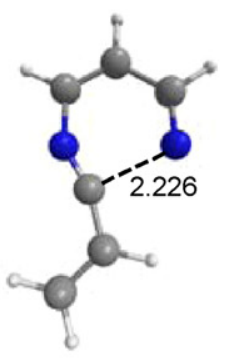

TS D7- VP1

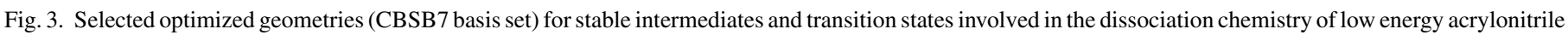
dimer radical cations. 


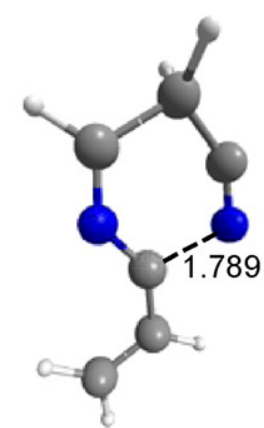

TS D4 - D5

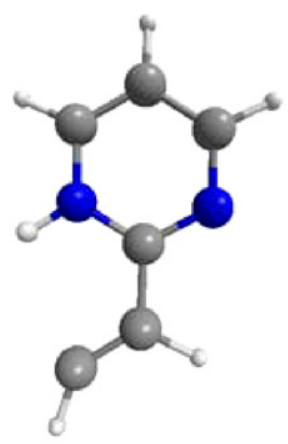

VP1a

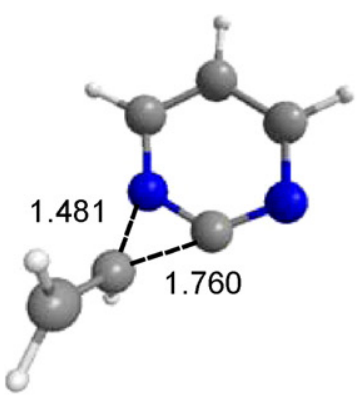

TS VP1 - VP2

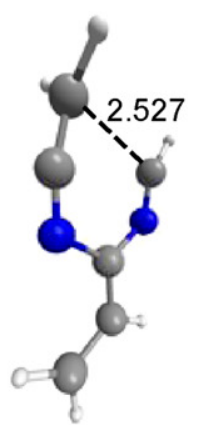

TS D5 - D8

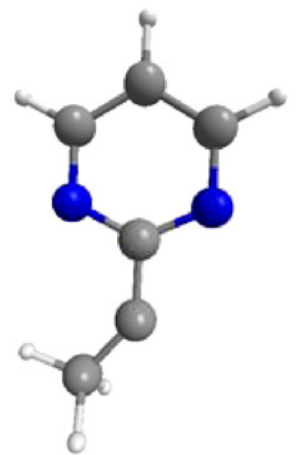

VP1b

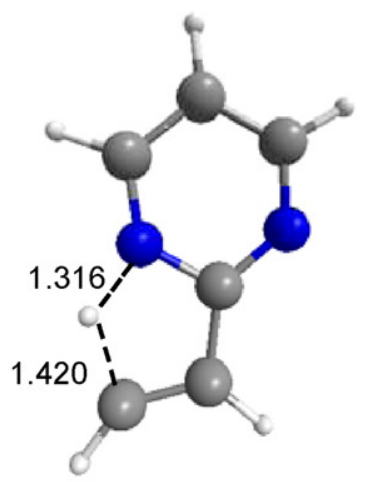

TS VP1 - VP1a

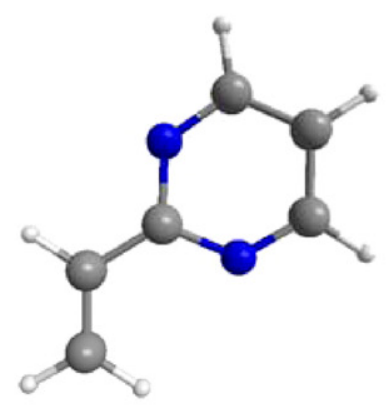

VP1

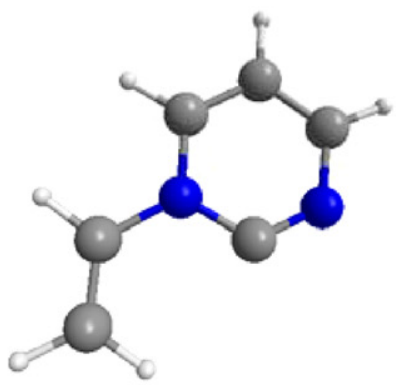

VP2

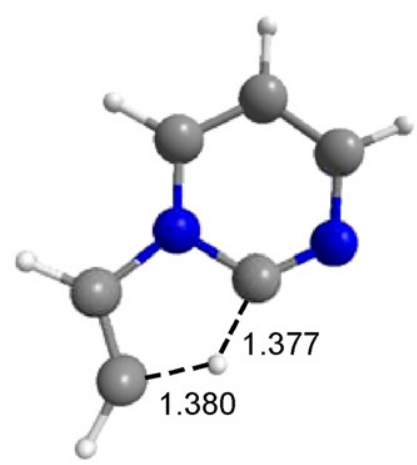

TS VP2 - VP2a

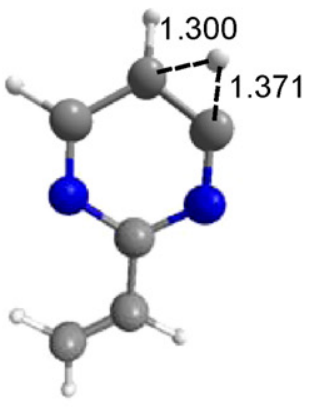

TS D5 - VP1

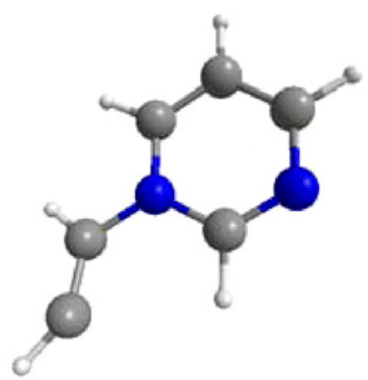

VP2a

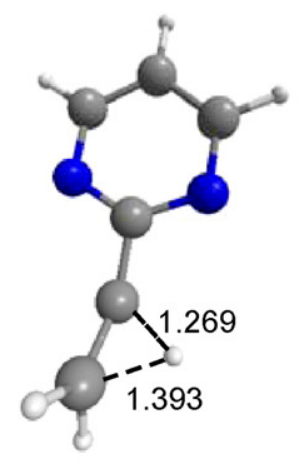

TS VP1 - VP1b

Fig. 3. (Continued).

immediate precursor for the loss of $\mathrm{C}_{2} \mathrm{H}_{2}$, see Scheme 7. Another route to the formation of VP1 involves the facile ring closure of ions D7 in Scheme 5. However, the minimum energy requirement for the transformation D1 $\rightarrow \mathrm{D} 7$, lies at $336 \mathrm{kcal} \mathrm{mol}^{-1}$, some $10 \mathrm{kcal} \mathrm{mol}^{-1}$ above the transformation D1 $\rightarrow$ D4. Considering the energy requirements for the competing losses of $\mathrm{H}^{\bullet}$ and $\mathrm{HCN}$, see Scheme 7, we see that this transformation is not a viable option.

Ion VP1 can readily lose $\mathrm{C}_{2} \mathrm{H}_{2}$ through a simple $1,4-\mathrm{H}$ shift to VP1a to generate the distonic pyrimidine isomer PY2 whose energy level lies at $318 \mathrm{kcal} \mathrm{mol}^{-1}$. To generate the slightly more stable pyrimidine ion PY1, the 2-vinylpyrimidine ion VP1 may first go through a 1,2 vinyl-shift at $311 \mathrm{kcal} \mathrm{mol}^{-1}$ (TS VP1-VP2 in Scheme 7). The resulting stable distonic isomer VP2 may then dissociate into PY1 $+\mathrm{C}_{2} \mathrm{H}_{2}$ via a low-lying 1,4-
$\mathrm{H}$ shift analogous to the VP1-VP1a shift. Thus, the formation of both PY1 and PY2 is energetically possible since the activation energy for the 1,2-vinylidene shift turns out to be relatively small $\left(43 \mathrm{kcal} \mathrm{mol}^{-1}\right)$. Our collision experiments show that the peak at $m / z, 80$ in Fig. $1 \mathrm{~b}$ indeed represents a mixture of isomers PY1 and PY2. Note that the interconversion of PY2 and PY1 via a 1,2-H shift is not feasible: the activation energy for this isomerization is prohibitively high, $65 \mathrm{kcal} \mathrm{mol}^{-1}$, as has been previously calculated by Lavorato et al. [3].

One further point deserves comment: following the proposal of Scheme 7, the deuterated dimer ions generated from acrylonitrile-2-d, $\mathrm{CH}_{2}=\mathrm{CDC} \equiv \mathrm{N}$, are expected to lose $\mathrm{C}_{2} \mathrm{HD}$. The $m / z, 81$ peak in the inset of Fig. 1b, part of which originates from the loss $\mathrm{HCN}$, shows that this is indeed the case. However, loss of $\mathrm{C}_{2} \mathrm{H}_{2}(\mathrm{~m} / \mathrm{z}$ 82) is also observed, indicating that 


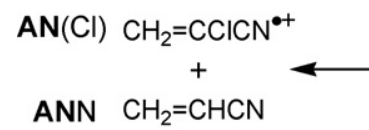

[332]

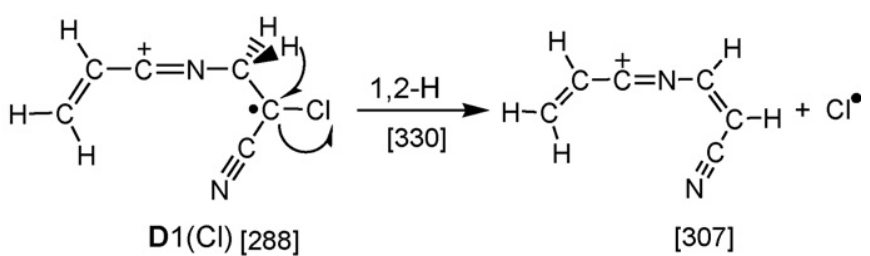

Scheme 8 the vinyl hydrogens in ion VP1 undergo exchange. Our calculations rationalize such an exchange via recurrent 1,2-H shifts between VP1 and VP1b (see Scheme 7 and Fig. 3), with a TS at $313 \mathrm{kcal} \mathrm{mol}^{-1}$.

\subsubsection{Loss of $H^{\bullet}$ and loss of $H C N$}

Our computational analysis indicates that the loss of $\mathrm{H}^{\bullet}$ proceeds from D1 to D4, yielding the $\mathrm{m} / \mathrm{z} 105$ ion structure depicted in Scheme 7. The thermochemical threshold for these dissociation products lies at $330 \mathrm{kcal} \mathrm{mol}^{-1}$ but this reaction was calculated to have a small reverse activation energy of $2 \mathrm{kcal} \mathrm{mol}^{-1}$. Note that the TS D5 $\rightarrow$ VP1 at $327 \mathrm{kcal} \mathrm{mol}^{-1}$ was found to be about $5 \mathrm{kcal} \mathrm{mol}^{-1}$ lower in energy than the TS for this dissociation.

The energetically most favourable path for the HCN loss involves ring-opening of D5 (TS at $309 \mathrm{kcal} \mathrm{mol}^{-1}$ ) to generate ion D8 (structure shown in Fig. 3) at $308 \mathrm{kcal} \mathrm{mol}^{-1}$. This ion can lose $\mathrm{HCN}$ without a reverse barrier yielding the linear $\mathrm{m} / \mathrm{z} 79$ ion depicted in Scheme 7. The energy requirement of this reaction is the same as that for the pyrimidine formation.

\subsubsection{The mixed dimer ion of acrylonitrile and \\ 2-chloroacrylonitrile}

Further support for the mechanistic proposal of Scheme 7 comes from a brief analysis of the dissociation behaviour of the dimer ion of acrylonitrile and 2-chloroacrylonitrile. The ionization energy of the chloro compound is lower than that of the parent nitrile $(11.58 \mathrm{eV}$ versus $11.91 \mathrm{eV}$ [17c]. Therefore, the chloro analogue of ion $\mathrm{D} 1$ depicted in the scheme below, $\mathrm{D} 1(\mathrm{Cl})$, is expected to be the principal species in this system of ions. The metastable dimer ions show only two reactions: (i) formation of $\mathrm{C}_{6} \mathrm{H}_{5} \mathrm{~N}_{2}{ }^{+}$ions $(\mathrm{m} / \mathrm{z}, 105)$ by loss of $\mathrm{Cl}^{\bullet}$ and (ii) formation of 2-chloroacrylonitrile ions $(\mathrm{m} / \mathrm{z}, 87)$ by loss of acrylonitrile.

Loss of $\mathrm{Cl}^{\bullet}$ dominates the MI spectrum: the $\mathrm{m} / \mathrm{z}, 105: \mathrm{m} / \mathrm{z} 87$ peak intensity ratio is $4: 1$. However, this ratio reverses to $1: 4$ in the CID spectrum of the dimer ions and $m / z 87$ is now the base peak. To probe the structure of the $m / z 105$ product ions we obtained their CID mass spectrum and found it to be identical with that of the $\mathrm{m} / \mathrm{z} 105$ ions generated by loss of $\mathrm{H}^{\bullet}$ from ions D1 in Scheme 7. These observations indicate that the $\mathrm{Cl}^{\bullet}$ loss is not a direct bond cleavage but rather occurs upon a 1,2- $\mathrm{H}$ shift in ions $\mathrm{D} 1(\mathrm{Cl})$, as depicted in Scheme 8.

The product enthalpies for the two dissociation reactions presented in the scheme (CBS-QB3 results Table 1) indicate that the two reactions can only compete if the $1,2-\mathrm{H}$ shift barrier preceding the $\mathrm{Cl}^{\bullet}$ loss is sufficiently high. This is indeed the case: our B3LYP/CBSB7 calculations predict the barrier to lie at $330 \mathrm{kcal} \mathrm{mol}^{-1}$ which allows the two processes to compete.
However, once ions $\mathrm{D} 1(\mathrm{Cl})$ have undergone the 1,2-H shift, immediate dissociation by loss of $\mathrm{Cl}^{\bullet}$ ensues because the reaction is strongly exothermic. This is not the case for the loss of $\mathrm{H}^{\bullet}$ from D1 which is slightly endothermic, see Scheme 7. This would explain why ions $\mathrm{D} 1(\mathrm{Cl})$ do not further rearrange to lose $\mathrm{HCN}$ and $\mathrm{C}_{2} \mathrm{H}_{2}$ whereas ions D1 do.

Finally, we note that metastable ions $\mathrm{D} 1(\mathrm{Cl})$ do not dissociate, via the chloro analogue of HBRC- 1 , into $\mathrm{CH}_{2}=\mathrm{CHC} \equiv$ $\mathrm{NH}^{+}+{ }^{\bullet} \mathrm{CH}=\mathrm{C}(\mathrm{C} 1) \mathrm{C} \equiv \mathrm{N}$ although the energy requirement for this reaction, $329 \mathrm{kcal} \mathrm{mol}^{-1}$, is $3 \mathrm{kcal} \mathrm{mol}^{-1}$ lower than that for the back dissociation (Table 1). This is not really surprising considering that in this system too the self-protonation reaction is expected to involve reverse activation energy.

\section{Summary}

Our combined computational and experimental study shows that the interaction of an acrylonitrile ion with its neutral counterpart leads to hydrogen-bridged ion-dipole complexes which may undergo self-protonation (but not self-catalysis) or else isomerize into the very stable covalently bound species D1 of Scheme 7. D1 ions act as the starting point configuration for the reactions that lead to the losses of $\mathrm{H}^{\bullet}, \mathrm{HCN}$ and $\mathrm{C}_{2} \mathrm{H}_{2}$.

The latter process involves a crucial cyclization step that ultimately yields ionized pyrimidine in admixture with its 2ylide isomer. This process may be relevant in the context of the quest for the prebiotic pyrimidine molecule in astrochemistry. Neutralization of the isomeric ions by charge exchange with molecular targets in the $\mathrm{keV}$ translational energy regime yields pyrimidine and its 2-ylide as stable neutral species [3]. The 2 -ylide does not convert into the more stable pyrimidine by an intramolecular 1,2-H shift [3] but this isomerization may readily occur by intermolecular interaction, e.g., with $\mathrm{H}_{3} \mathrm{O}^{+}$on an icy surface. Such a surface could also promote electron-ion recombination followed by isomerization as has been proposed for the formation of acetic acid in space in a recent SIFT study [7b,26].

Finally we note that a detailed analysis [27] of the ion-molecule reaction of acrylonitrile with $\mathrm{HCN}$ indicates that ionized pyrimidine could be generated via an analogous mechanism.

\section{Acknowledgements}

JKT thanks the Natural Sciences and Engineering Research Council of Canada (NSERC) for continuing financial support and Dr M.A. Trikoupis (OME Toronto) and Richard Lee for valuable discussions. PJAR and HKE thank the Netherlands 
Organization for Scientific research (NWO) for making available the SGI TERAS computer of SARA (Amsterdam).

\section{References}

[1] (a) M.A. Trikoupis, P.J.A. Ruttink, P.C. Burgers, J.K. Terlouw, Int. J. Mass Spectrom. 217 (2002) 97;

(b) M.A. Trikoupis, P.J.A. Ruttink, P.C. Burgers, J.K. Terlouw, Eur. J. Mass Spectrom. 10 (2004) 801.

[2] (a) For selected recent references see: G. van der Rest, P. Mourgues, H.E. Audier, Int. J. Mass Spectrom. 231 (2004) 83;

(b) C.Y. Wong, P.J.A. Ruttink, P.C. Burgers, J.K. Terlouw, Chem. Phys. Lett. 390 (2004) 176;

C.Y. Wong, P.J.A. Ruttink, P.C. Burgers, J.K. Terlouw, Chem. Phys. Lett. 387 (2004) 204;

(c) X. Wang, J.L. Holmes, Can. J. Chem. 83 (2005) 1903;

(d) P.C. Burgers, P.J.A. Ruttink, Int. J. Mass Spectrom. 242 (2005) 49;

(e) For an early review see: D.K. Bohme, Int. J. Mass Spectrom. 115 (1992) 95.

[3] D.J. Lavorato, T.K. Dargel, W. Koch, G.A. McGibbon, H. Schwarz, J.K. Terlouw, Int. J. Mass Spectrom. 210-211 (2001) 43.

[4] E. Herbst, Chem. Soc. Rev. 30 (2001) 168.

[5] (a) F.F. Gardner, G. Winnewisser, Astrophys. J. 195 (1975) L127; (b) H.E. Matthews, T.J. Sears, Astrophys. J. 272 (1983) 149;

(c) F. Raulin, Adv. Space Res. 7 (1987) 71;

(d) M.C. Pietrogrande, P. Coll, R. Sternberg, C. Szopa, R. NavarroGonzales, C. Vidal-Madjar, F. Dondi, J. Chromatogr. A 939 (2001) 69.

[6] P.M. Woods, T.J. Millar, A.A. Zijlstra, E. Herbst, Astrophys. J. 574 (2002) L167.

[7] (a) S. Petrie, D.K. Bohme, Top. Curr. Chem. 225 (2003) 37; (b) S. Petrie, D.K. Bohme, Mass Spectrom. Rev., in press.

[8] C.F. Chyba, P.J. Thomas, L. Brookshaw, C. Sagan, Science 249 (1990) 366.

[9] Y.-J. Kuan, S.B. Charnley, H.-C. Huang, Z. Kisiel, P. Ehrenfreund, W.-L. Tseng, C.-H. Yan, Adv. Space Res. 33 (2004) 31.

[10] (a) M.N. Simon, M. Simon, Astrophys. J. 184 (1973) 757;

(b) Y.-J. Kuan, C.-H. Yan, S.B. Charnley, Z. Kisiel, P. Ehrenfreund, H.-C. Huang, Royal Astro. Soc. 345 (2003) 650;

(c) Z. Peeters, O. Botta, S.B. Charnley, Z. Kisiel, Y.-J. Kuan, P. Ehrenfreund, Astron. Astrophys. 433 (2005) 583.

[11] H.F. van Garderen, P.J.A. Ruttink, P.C. Burgers, G.A. McGibbon, J.K. Terlouw, Int. J. Mass Spectrom. Ion Proc. 121 (1992) 159.

[12] (a) J.W. Ochterski, G.A. Petersson, J.A. Montgomery Jr., J. Chem. Phys. 104 (1996) 2598;

(b) J.A. Montgomery Jr., M.J. Frisch, J.W. Ochterski, G.A. Petersson, J. Chem. Phys. 112 (2000) 6532.

[13] (a) M.J. Frisch, G.W. Trucks, H.B. Schlegel, G.E. Scuseria, M.A. Robb, J.R. Cheeseman, V.G. Zakrzewski, J.A. Montgomery Jr., R.E. Stratmann, J.C. Burant, S. Dapprich, J.M. Millam, A.D. Daniels, K.N. Kudin, M.C. Strain, O. Farkas, J. Tomasi, V. Barone, M. Cossi, R. Cammi, B. Mennucci, C. Pomelli, C. Adamo, S. Clifford, J. Ochterski, G.A. Petersson, P.Y. Ayala, Q. Cui, K. Morokuma, N. Rega, P. Salvador, J.J. Dannenberg, D.K. Malick, A.D. Rabuck, K. Raghavachari, J.B. Foresman, J. Cioslowski, J.V. Ortiz, A.G. Baboul, B.B. Stefanov, G. Liu, A. Liashenko, P. Piskorz, I. Komaromi, R. Gomperts, R.L. Martin, D.J. Fox, T. Keith, M.A. Al-Laham, C.Y. Peng, A. Nanayakkara, M. Challacombe, P.M.W. Gill, B. Johnson,
W. Chen, M.W. Wong, J.L. Andres, C. Gonzalez, M. Head-Gordon, E.S. Replogle, J.A. Pople, Gaussian 98 Revision A.11, Gaussian Inc., Pittsburg, PA, 1998;

(b) M.J. Frisch, G.W. Trucks, H.B. Schlegel, G.E. Scuseria, M.A. Robb, J.R. Cheeseman, J.A. Montgomery Jr., T. Vreven, K.N. Kudin, J.C. Burant, J.M. Millam, S.S. Iyengar, J. Tomasi, V. Barone, B. Mennucci, M. Cossi, G. Scalmani, N. Rega, G.A. Petersson, H. Nakatsuji, M. Hada, M. Ehara, K. Toyota, R. Fukuda, J. Hasegawa, M. Ishida, T. Nakajima, Y. Honda, O. Kitao, H. Nakai, M. Klene, X. Li, J.E. Knox, H.P. Hratchian, J.B. Cross, V. Bakken, C. Adamo, J. Jaramillo, R. Gomperts, R.E. Stratmann, O. Yazyev, A.J. Austin, R. Cammi, C. Pomelli, J.W. Ochterski, P.Y. Ayala, K. Morokuma, G.A. Voth, P. Salvador, J.J. Dannenberg, V.G. Zakrzewski, S. Dapprich, A.D. Daniels, M.C. Strain, O. Farkas, D.K. Malick, A.D. Rabuck, K. Raghavachari, J.B. Foresman, J.V. Ortiz, Q. Cui, A.G. Baboul, S. Clifford, J. Cioslowski, B.B. Stefanov, G. Liu, A. Liashenko, P. Piskorz, I. Komaromi, R.L. Martin, D.J. Fox, T. Keith, M.A. Al-Laham, C.Y. Peng, A. Nanayakkara, M. Challacombe, P.M.W. Gill, B. Johnson, W. Chen, M.W. Wong, C. Gonzalez, J.A. Pople, Gaussian 03 (Revision C.02), Gaussian, Inc., Wallingford, CT, 2004.

[14] GAMESS-UK is a package of ab initio programs written by M.F. Guest, J.H. van Lenthe, J. Kendrick, K. Schoffel, P. Sherwood, with contributions from R.D. Amos, R.J. Buenker, H.J.J. van Dam, M. Dupuis, N.C. Handy, I.H. Hillier, P.J. Knowles, V. Bonacic-Koutecky, W. von Niessen, R.J. Harrison, A.P. Rendell, V.R. Saunders, A.J. Stone, D.J. Tozer, A.H. de Vries. The package is derived from the original GAMES S code due to M. Dupuis, D. Spangler, J. Wendolowski, NRCC Software Catalogue 1, vol. 1, Program No. QG01 (GAMESS), 1980.

[15] L.N. Heydorn, Y. Ling, G. de Oliveria, J.M.L. Martin, Ch. Lifshitz, J.K. Terlouw, Zeitschrift für Physikalische Chemie 215 (2001) 141.

[16] P.M. Mayer, C.J. Parkinson, D.M. Smith, L. Radom, J. Chem. Phys. 108 (1998) 604.

[17] (a) D.R. Lide (Ed.), Handbook of Chemistry and Physics, 87th ed., CRC Press, Boca Raton, 2006;

(b) E.P.L. Hunter, S.G. Lias, J. Phys. Chem. Ref. Data 27 (1998) 3; (c) NIST Chemistry WebBook, July 2006. National Institute of Standards and Technology, Gaithersburg, MD, 20899 (http://webbook.nist.gov); (d) Y.-R. Luo, Handbook of Dissociation Energies in Organic Compounds, CRC Press, Boca Raton, 2003;

(e) S.G. Lias, J.E. Bartmess, J.F. Liebman, J.L. Holmes, R.O. Levin, W.G. Maillard, J. Phys. Chem. Ref. Data 17 (Suppl. 1) (1988).

[18] T. Bally, G.N. Sastry, J. Phys. Chem. A 101 (1997) 7923.

[19] J.W. Gauld, L. Radom, J. Am. Chem. Soc. 119 (1997) 9831.

[20] P.C. Burgers, J.K. Terlouw, in: N.M.M. Nibbering (Ed.), Encyclopedia of Mass Spectrometry, vol. 4, Elsevier, Amsterdam, 2005, p. 173.

[21] M. Ichihashi, Y. Sadanaga, T. Kondow, J. Chem. Phys. A 102 (1998) 8287.

[22] M. Meot-Ner, L.W. Sieck, J. Am. Chem. Soc. 113 (1991) 4448.

[23] T. Baer, W.L. Hase, Unimolecular Reaction Dynamics, Theory and Experiments, Oxford University Press, New York, 1996.

[24] T. Baer, J.A. Booze, in: W.L. Hase (Ed.), Advances in Classical Trajectory Methods, vol. 2, JAI Press Inc., Hampton Hill, 1994, p. 1.

[25] D.J. Lavorato, J.K. Terlouw, G.A. McGibbon, T.K. Dargel, W. Koch, H. Schwarz, Int. J. Mass Spectrom. 179-180 (1998) 7.

[26] G. Orlova, V. Blagojevic, D.K. Bohme, J. Phys. Chem. A 110 (2006) 8266.

[27] H.K. Ervasti, K.J. Jobst, P.C. Burgers, P.J.A. Ruttink, J.K. Terlouw, in preparation. 